\title{
Mid-tropospheric $\delta$ D observations from IASI/MetOp at high spatial and temporal resolution
}

\author{
J.-L. Lacour ${ }^{1}$, C. Risi ${ }^{2}$, L. Clarisse ${ }^{1}$, S. Bony ${ }^{2}$, D. Hurtmans ${ }^{1}$, C. Clerbaux ${ }^{3,1}$, and P.-F. Coheur ${ }^{1}$ \\ ${ }^{1}$ Spectroscopie de l'Atmosphère, Service de Chimie Quantique et Photophysique,Université Libre de Bruxelles, Belgium \\ ${ }^{2}$ LMD/IPSL, CNRS, Paris, France \\ ${ }^{3}$ UPMC Univ. Paris 06, Université Versailles St.-Quentin, CNRS/INSU, LATMOS-IPSL, Paris, France
}

Correspondence to: J.-L. Lacour (jlacour@ulb.ac.be)

Received: 18 April 2012 - Published in Atmos. Chem. Phys. Discuss.: 25 May 2012

Revised: 12 October 2012 - Accepted: 23 October 2012 - Published: 16 November 2012

\begin{abstract}
In this paper we retrieve atmospheric $\mathrm{HDO}, \mathrm{H}_{2} \mathrm{O}$ concentrations and their ratio $\delta \mathrm{D}$ from IASI radiances spectra. Our method relies on an existing radiative transfer model (Atmosphit) and an optimal estimation inversion scheme, but goes further than our previous work by explicitly considering correlations between the two species. A global HDO and $\mathrm{H}_{2} \mathrm{O}$ a priori profile together with a covariance matrix were built from daily LMDz-iso model simulations of HDO and $\mathrm{H}_{2} \mathrm{O}$ profiles over the whole globe and a whole year. The retrieval parameters are described and characterized in terms of errors. We show that IASI is mostly sensitive to $\delta \mathrm{D}$ in the middle troposphere and allows retrieving $\delta \mathrm{D}$ for an integrated 3-6 km column with an error of $38 \%$ on an individual measurement basis. We examine the performance of the retrieval to capture the temporal (seasonal and short-term) and spatial variations of $\delta \mathrm{D}$ for one year of measurement at two dedicated sites (Darwin and Izaña) and a latitudinal band from $-60^{\circ}$ to $60^{\circ}$ for a 15 day period in January. We report a generally good agreement between IASI and the model and indicate the capabilities of IASI to reproduce the large scale variations of $\delta \mathrm{D}$ (seasonal cycle and latitudinal gradient) with good accuracy. In particular, we show that there is no systematic significant bias in the retrieved $\delta \mathrm{D}$ values in comparison with the model, and that the retrieved variability is similar to the one in the model even though there are certain local differences. Moreover, the noticeable differences between IASI and the model are briefly examined and suggest modeling issues instead of retrieval effects. Finally, the results further reveal the unprecedented capabilities of IASI to capture shortterm variations in $\delta \mathrm{D}$, highlighting the added value of the sounder for monitoring hydrological processes.
\end{abstract}

\section{Introduction}

Water vapor is a key gas for the climate system. It is the strongest absorber of infrared radiation in our atmosphere, contributing to approximately $50 \%$ of the total greenhouse effect (Schmidt et al., 2010; Kiehl and Trenberth, 1997). Moist processes also play a key role in controlling the largescale atmospheric circulation (Randall et al., 1989; Frierson, 2007) and its sensitivity to climate forcing (Kang et al., 2008; Zhang et al., 2010). Even though hydrological processes have been studied abundantly, there is still an insufficient understanding of the factors controlling water amount (Sherwood et al., 2010; Schneider et al., 2010b). As major climate feedbacks (cloud and water vapor feedbacks) are associated with tropospheric water vapor (Soden and Held, 2006; Bony et al., 2006), there is a need to better assess the mechanisms that control the humidity distribution in the troposphere.

Because vapor pressure depends on the mass of the water molecules, there is a fractionation of the different isotopologues during evaporation and condensation processes: heavier isotopologues $\left(\mathrm{H}_{2}{ }^{18} \mathrm{O}, \mathrm{H}_{2}{ }^{17} \mathrm{O}\right.$ and $\left.\mathrm{HDO}\right)$ have a lower vapor pressure and will preferentially condensate, leading to a depletion of the heavier isotopologues in an airmass that experiences condensation. The isotopic composition of an air parcel therefore gives a fingerprint of the history of the phase changes. Because the factors that control the water vapor amount also control the isotopic fractionation of the air parcel, an accurate measurement of isotopologues ratio is invaluable for the study of humidity processes. Measurements from various instruments (cavity ring down spectrometers, ground-based FTIR, atmospheric sounders) have

Published by Copernicus Publications on behalf of the European Geosciences Union. 
demonstrated this and have been used to examine, for instance, air mass mixing (Noone et al., 2011), transport processes (Strong et al., 2007), evaporation of hydro-meteors (Worden et al., 2007), cloud processes (Lee et al., 2011) and intra-seasonal climate variability in the tropics (Kurita et al., 2011; Berkelhammer et al., 2012). Isotopic concentrations are commonly expressed as $\delta$ values that define the relative deviation of the ratio with respect to a standard ratio. For example, the concentration in $\mathrm{HDO}$ with respect to $\mathrm{H}_{2} \mathrm{O}$ is expressed as

$\delta \mathrm{D}=1000\left(\frac{\frac{\mathrm{HDO}}{\mathrm{H}_{2} \mathrm{O}}}{\mathrm{VSMOW}}-1\right)$,

where VSMOW (Vienna Standard Mean Ocean Water) is the reference standard for water isotope ratios (Craig, 1961).

Today, several space-borne instruments can capture isotopic variations. The Tropospheric Emission Spectrometer (TES) and the SCanning Imaging Absorption spectroMeter for Atmospheric CartograpHY (SCIAMACHY) instruments have been the first to provide global distributions of $\delta \mathrm{D}$ representative of the mid-troposphere (Worden et al., 2006, 2007) and the boundary layer (Frankenberg et al., 2009), respectively. The inter comparisons of observations with isotopologues-enabled atmospheric general circulation models have demonstrated the added value of such measurements to identify biases in the modeling of the isotopic fractionation and thus to better characterize hydrological processes (Risi et al., 2010a, 2012a,b; Yoshimura et al., 2011).

Two other space-based remote sensing instruments can measure the isotopic composition in the troposphere: the Infrared Atmospheric Sounding Interferometer on board MetOp (Clerbaux et al., 2009) and the Thermal And Near infrared Sensor for carbon Observation (TANSO) on board GOSAT (C. Frankenberg, personal communication, 2012). IASI is especially attractive for this purpose, considering its unprecedented spatial coverage and temporal sampling (see below), and the long-term character of the mission with $15 \mathrm{yr}$ of planned continuous data. The potential of IASI to measure $\delta \mathrm{D}$ was first investigated by Herbin et al. (2009) who carried out a sensitivity study. More recently retrievals of $\delta \mathrm{D}$ applying IASI spectra have been presented and compared to ground-based FTIR measurements (Schneider and Hase, 2011).

This paper focuses on the retrieval of $\delta \mathrm{D}$ from IASI spectral radiances and their evaluation. Tropospheric water vapour concentrations are very variable, while the $\mathrm{HDO} / \mathrm{H}_{2} \mathrm{O}$ ratio is rather stable in comparison. For measuring water vapour isotopologues ratios, we thus need a technique that is sensitive over a large dynamic range, and at the same time precise enough to capture small isotopic variations. Since it is difficult for any measurement technique to optimally meet both requirements; tropospheric water vapor isotopologues ratio measurements are very difficult. We use a radiative transfer model that is similar to the one used in the
Herbin et al. (2009) study. Their retrieval was based on a simultaneous but independent retrieval of $\mathrm{H}_{2}{ }^{16} \mathrm{O}$ and HDO. Here we constrain the retrieval with a full covariance matrix that takes into account the correlations between $\mathrm{H}_{2}{ }^{16} \mathrm{O}$ and $\mathrm{HDO}$. This new retrieval methodology named the $\mathrm{HDO} / \mathrm{H}_{2} \mathrm{O}$ correlated approach is described in Sect. 3. In that section we also extensively characterize the retrievals in terms of vertical sensitivity and errors. In Sect. 2 we first briefly recall some of the main IASI characteristics. In Sect. 4 we describe the first retrieval results, focusing on the ability of IASI to capture the $\delta \mathrm{D}$ seasonal cycle but also rapid temporal variations at two sites (Izaña $28^{\circ} 18^{\prime} \mathrm{N} 16^{\circ} 29^{\prime} \mathrm{W}$, and Darwin $12^{\circ} 27^{\prime} \mathrm{S}$ $130^{\circ} 50^{\prime} \mathrm{E}$ ), as well as latitudinal variations over the globe. The retrievals are evaluated by comparing the retrieved values to those modeled by the LMDz-iso General Circulation Model (GCM) (Risi et al., 2010b).

\section{IASI observations}

IASI is a Fourier transform spectrometer on board the METOP series of European meteorological polar-orbit satellites. The first model, designed to provide $5 \mathrm{yr}$ of global-scale observations, was launched in October 2006. A second and a third instrument will be launched in 2012 and 2016, respectively. IASI measures a large part of the thermal infrared spectral region $\left(645-2760 \mathrm{~cm}^{-1}\right)$ continuously at a medium spectral resolution $\left(0.5 \mathrm{~cm}^{-1}\right.$ apodized $)$. It has a low noise of $0.1-0.2 \mathrm{~K}$ for a reference blackbody at $280 \mathrm{~K}$, with the lower noise values in the useful range for $\delta \mathrm{D}$ retrievals (Hilton et al., 2012). Primarily designed for operational meteorological soundings with a high level of accuracy, the instrument achieves a global coverage twice a day (orbits crossing the Equator at 09:30 and 21:30 LT) with a relatively small pixel size of $12 \mathrm{~km}$ diameter at nadir, larger at off nadir viewing angles. IASI makes about 1.3 million measurements per day and coping with this volume of data is very challenging, requiring important computing resources coupled with a fast radiative transfer model (e.g., Hurtmans et al., 2012). In this study we primarily aim at characterizing the new $\delta \mathrm{D}$ retrievals and therefore we have analyzed observations over selected regions.

The main isotopologues of water $\left(\mathrm{H}_{2}{ }^{16} \mathrm{O}, \mathrm{H}_{2}{ }^{18} \mathrm{O}\right.$ and HDO) have large absorption bands in the thermal infrared region (Rothman et al., 2003; Toth, 1999). Spectral signatures of these species are well detected by IASI (Herbin et al., 2009) despite the instrument's medium spectral resolution. $\delta^{18} \mathrm{O}$ retrievals remain challenging as its small variations in the atmosphere require very high accuracy. $\delta \mathrm{D}$ variations are larger by one order of magnitude and are therefore targeted here. Figure 1 shows part of an IASI spectrum with the spectral windows used in the retrieval (red curve). These have been chosen to avoid major interferences of $\mathrm{CH}_{4}$ and $\mathrm{N}_{2} \mathrm{O}$ in this range. Note that these two small spectral ranges differ from the large spectral range approach 


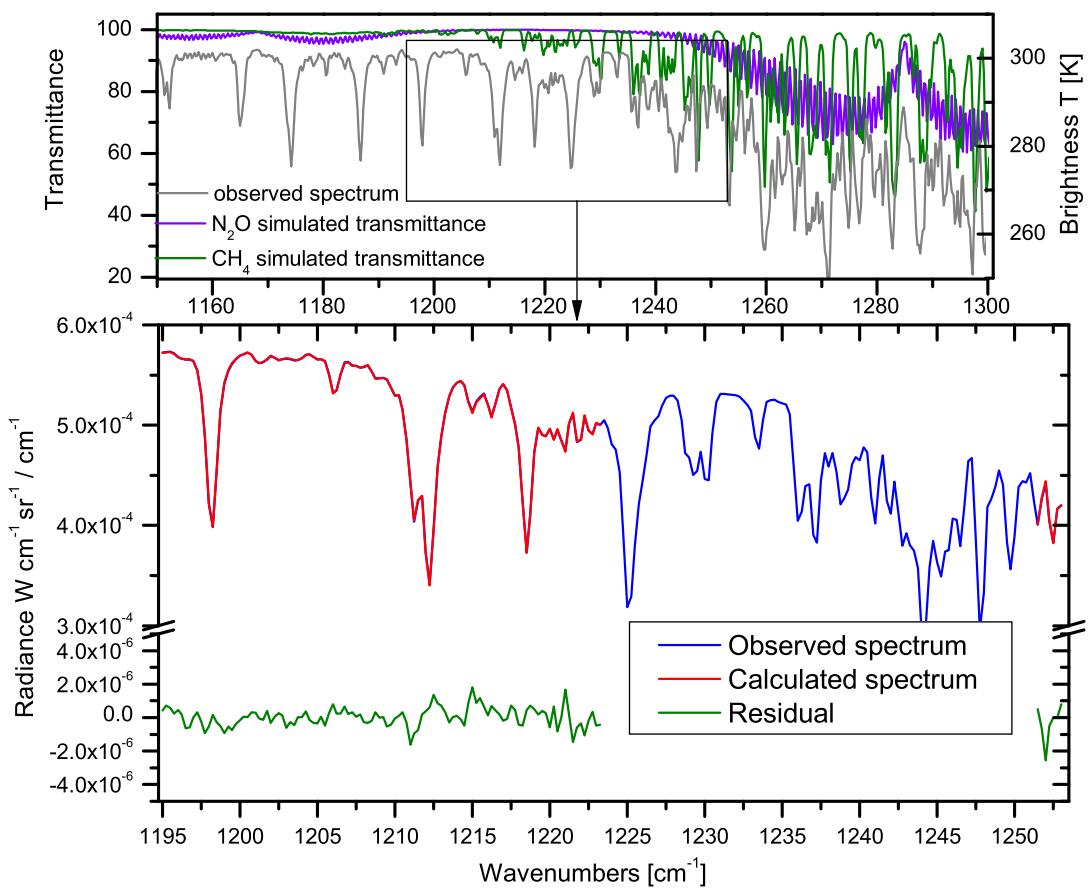

Fig. 1. Spectral window used in the retrieval. Top panel: IASI spectra (black curve) in brigthness temperature with the spectral signature of $\mathrm{CH}_{4}$ and $\mathrm{N}_{2} \mathrm{O}$. Bottom panel: example of an IASI observed spectra (blue curve), the calculated spectrum (red curve) and the residual (green curve). The gap between 1223 and $1251 \mathrm{~cm}^{-1}$ avoids major $\mathrm{CH}_{4}$ and $\mathrm{N}_{2} \mathrm{O}$ interferences.

of Schneider and Hase (2011), which was selected to maximize the level of information. The chosen channels include a sufficient number of baseline channels needed to fit the water continuum, but at the same time optimize the computational time.

\section{Retrieval methodology}

To retrieve $\delta \mathrm{D}$ from IASI spectral radiances we used the optimal estimation method, mainly following the approach proposed by Worden et al. (2006) and Schneider et al. (2006). It involves retrieving $\mathrm{HDO}$ and $\mathrm{H}_{2} \mathrm{O}$ with an a priori covariance matrix that represents the variability of the two species but also contains information on the correlations between them. The retrieval performed on a $\log$ scale allows better constraint of the solution and minimization of error on the $\delta \mathrm{D}$ profile (Worden et al., 2006; Schneider et al., 2006; Schneider and Hase, 2011). The line-by-line radiative transfer model software Atmosphit developed at the Universite Libre de Bruxelles and used in our first attempt to retrieve $\delta$ D from IASI (Herbin et al., 2009) has been adapted to allow this $\mathrm{HDO} / \mathrm{H}_{2} \mathrm{O}$ correlated approach.

Using correlations between $\log (\mathrm{HDO})$ and $\log \left(\mathrm{H}_{2} \mathrm{O}\right)$ helps to constrain the joint $\mathrm{HDO} / \mathrm{H}_{2} \mathrm{O}$ retrieval to a physically meaningful solution, as demonstrated on TES measurements (Worden et al., 2006, 2007, 2012), ground based measurements (Schneider et al., 2010a, 2006), and a limited number of IASI measurements (Schneider and Hase, 2011). However, it is anticipated that the retrieval will greatly depend on the choices of the retrieval setup. We discuss our choice of a priori constraint specifically in Sect. 3.3. The choice of retrieval parameters also affects the vertical resolution and the error budget associated to the retrieval; this is discussed in Sect. 3.2.

\subsection{General description}

An atmospheric state vector can be related analytically to a corresponding measurement vector using a forward function describing the physics of the measurement. This relationship can be written as

$\boldsymbol{y}=\mathbf{F}(\boldsymbol{x}, \boldsymbol{b})+\boldsymbol{\epsilon}$,

where $\boldsymbol{y}$ is the measurement vector (in our case, the IASI radiances), $\boldsymbol{\epsilon}$ the instrumental noise, $\boldsymbol{x}$ the state vector that contains the parameters to be retrieved, and $\boldsymbol{b}$ the vector containing all other model parameters impacting the measurement (for instance, interfering species, pressure and temperature profiles). $\mathbf{F}$ is the forward function.

In the case of a linear problem, the maximum a posteriori solution can be written per Rodgers (2000) as

$\hat{\boldsymbol{x}}=\boldsymbol{x}_{\mathrm{a}}+\left(\mathbf{K}^{T} \mathbf{S}_{\epsilon}^{-1} \mathbf{K}+\mathbf{S}_{\mathrm{a}}^{-1}\right)^{-1} \mathbf{K}^{T} \mathbf{S}_{\epsilon}^{-1}\left(\boldsymbol{y}-\mathbf{K} \boldsymbol{x}_{\mathrm{a}}\right)$,

where $\boldsymbol{x}_{\mathrm{a}}$ is the a priori state vector and $\mathbf{K}$ is the Jacobian containing the partial derivatives of the forward model elements 
with respect to the state vector element

$\mathbf{K}_{i j}=\frac{\partial \mathbf{F}_{i}(x)}{\partial x_{j}}$.

$\mathbf{S}_{\epsilon}$ is the measurement error covariance, and $\mathbf{S}_{\mathrm{a}}$ is the a priori covariance matrix. The retrieved state is therefore a combination of the measurement and the a priori state inversely weighted by their respective covariance matrices.

Retrieving atmospheric quantities from space measurements is often a non-linear problem that requires numerical methods to solve. For a moderately non-linear problem, which is the case here, the best estimate of the state vector can be found by iteration of

$$
\begin{aligned}
\boldsymbol{x}_{i+1}= & \boldsymbol{x}_{i}+\left(\mathbf{S}_{\mathrm{a}}^{-1}+\mathbf{K}_{i}^{T} \mathbf{S}_{\epsilon}^{-1} \mathbf{K}_{i}\right)^{-1} \mathbf{K}_{i}^{T} \mathbf{S}_{\epsilon}^{-1} \\
& {\left[\boldsymbol{y}-\mathbf{F}\left(\boldsymbol{x}_{i}\right)+\mathbf{K}_{i}\left(\boldsymbol{x}_{i}-\boldsymbol{x}_{\mathrm{a}}\right)\right] . }
\end{aligned}
$$

\subsection{Retrieval parameters}

We retrieve profiles of $\mathrm{HDO}$ and $\mathrm{H}_{2}{ }^{16} \mathrm{O}$ of the 10 first kilometers of the atmosphere in 10 discretized layers of $1 \mathrm{~km}$ thickness. The corresponding a priori profile is kept fixed in time and in space. The atmosphere from 10 to $24 \mathrm{~km}$ is defined and varies according to the EUMETSAT L2 water vapor profiles. We do not retrieve $\mathrm{HDO}$ and $\mathrm{H}_{2}{ }^{16} \mathrm{O}$ in this upper range of the atmosphere because in the spectral range used (from 1193 to $1223 \mathrm{~cm}^{-1}$ and from 1251 to $1253 \mathrm{~cm}^{-1}$ ); variations of the water concentrations fixed from the EUMETSAT L2 water product do not significantly affect the measurement. We note that our vertical grid is coarser than that used in previous studies (Schneider and Hase, 2011; Worden et al., 2012) so that some small improvements may be provided by using a finer griding; this at the cost of a longer calculation time. Methane (retrieved as a column) as well as surface temperature are also part of the state vector. We do not retrieve the temperature profiles as in Schneider and Hase (2011) and we instead use EUMETSAT L2 processor temperature profiles retrieved for each IASI field of view (Schlüssel et al., 2005), estimated with an error of $1.5 \mathrm{~K}$ at the surface, $0.6 \mathrm{~K}$ between 800 and $300 \mathrm{mb}$ and $1.5 \mathrm{~K}$ in the tropopause (Pougatchev et al., 2009). Spectrally resolved surface emissivities (on IASI sampling) are explicitly considered above land surfaces, using the monthly climatology of Zhou et al. (2011). We approximated the measurement noise covariance matrix as a diagonal matrix with an error $1 \sigma$ of $8 \times 10^{-9} \mathrm{~W} /\left(\mathrm{cm}^{2} \mathrm{~cm}^{-1} \mathrm{sr}\right)$. Only spectra with an EUMETSAT's level 2 cloud fraction below $10 \%$ have been considered in this study.

\subsection{The a priori information}

Retrieving the state vector $\boldsymbol{x}$ from Eq. (3) is in general an illposed problem and to obtain a physical meaningful solution we need to constrain the retrieval with a prior information. In the optimal estimation framework, the a priori information is a measure of the knowledge of the state vector prior to the measurement. The usual approach is to assume a Gaussian distribution of the state vector, which can then be characterized by a mean and covariance matrix. The covariance matrix describes to which extent parameters co-vary, for an ensemble of $\boldsymbol{n}$ vectors $\left\{y_{i}\right\}$. It is given by

$\mathbf{S}_{i, j}=\sum_{i, j}\left\{\left(y_{i}-\bar{y}\right)\left(y_{j}-\bar{y}\right)\right\} / n^{2}$.

Its diagonal elements are the variances of the individual parameters.

Here, our state vector contains $\log \left(\mathrm{H}_{2} \mathrm{O}\right)$ and $\log (\mathrm{HDO})$ profiles. Within one profile, different altitude levels are correlated. However, there are also strong correlations between $\log \left(\mathrm{H}_{2} \mathrm{O}\right)$ and $\log (\mathrm{HDO})$. These correlations can be captured in a total covariance matrix $\mathbf{S}_{\mathrm{a}}$, which can naturally be grouped into four sub-blocks as

$\mathbf{S}_{\mathrm{a}}=\left(\begin{array}{cc}\left(\mathbf{S}_{\mathrm{H}_{2} \mathrm{O}_{\mathrm{L}}}\right)_{1} & \left(\mathbf{S}_{\left(\mathrm{H}_{2} \mathrm{O}_{\mathrm{L}}, \mathrm{HDO}_{\mathrm{L}}\right)}\right)_{3} \\ \left(\mathbf{S}_{\left(\mathrm{HDO}_{\mathrm{L}}, \mathrm{H}_{2} \mathrm{O}_{\mathrm{L}}\right)}\right)_{4} & \left(\mathbf{S}_{\left.\mathrm{HDO}_{\mathrm{L}}\right)_{2}}\right.\end{array}\right)$,

where the two blocks $\mathbf{S}_{\mathrm{H}_{2} \mathrm{O}_{\mathrm{L}}}$ and $\mathbf{S}_{\mathrm{HDO}}$ are the covariance matrices of the $\log \left(\mathrm{H}_{2} \mathrm{O}\right)$ and $\log (\mathrm{HDO})$, respectively. The matrices $\mathbf{S}_{\left(\mathrm{H}_{2} \mathrm{O}_{\mathrm{L}}, \mathrm{HDO}_{\mathrm{L}}\right)}=\mathbf{S}_{\left(\mathrm{HDO}_{\mathrm{L}}, \mathrm{H}_{2} \mathrm{O}_{\mathrm{L}}\right)}^{T}$ contain the correlations between $\log \left(\mathrm{H}_{2} \mathrm{O}\right)$ and $\log (\mathrm{HDO})$.

The choice of the a priori information is critical in the regularization of an ill-posed problem (Rodgers, 2000). The best way to get adequate prior information is to derive the mean and covariance from independent measurements data at high spatial resolution. Only few measurements of $\delta \mathrm{D}$ vertical profiles (Ehhalt, 1974; Strong et al., 2007) as surface measurements (Galewsky et al., 2007, 2011; Johnson et al., 2011) are available. They are not representative for our purpose, which is to retrieve $\delta \mathrm{D}$ profiles over extended areas, covering polar to tropical latitudes. Therefore, to construct a priori information we used outputs from the isotopologuesenabled general circulation model LMDz (Risi et al., 2010b), which has demonstrated reasonably well its capabilities to capture water vapor and isotopic distributions at seasonal and intra-seasonal time scales (Risi et al., 2010a, 2012b). These simulations were nudged by ECMWF reanalyzed winds to simulate a day-to-day variability of weather regimes consistent with observations. To avoid spatial dependency of the results on the a priori profile, a single a priori state vector has been calculated as the mean of an ensemble of $\mathrm{HDO}$ and $\mathrm{H}_{2} \mathrm{O}$ simulated profiles representative of the whole globe and the whole year. The associated covariances $\left(\mathbf{S}_{\mathrm{HDO}_{\mathrm{L}}}, \mathbf{S}_{\mathrm{H}_{2} \mathrm{O}_{\mathrm{L}}}, \mathbf{S}_{\left.\mathrm{H}_{2} \mathrm{O}_{\mathrm{L}}, \mathrm{HDO}_{\mathrm{L}}\right)}\right.$ defined by Eq. 7$)$ have been computed to build the a priori covariance matrix. The $\mathrm{H}_{2} \mathrm{O}$, and $\delta \mathrm{D}$ a priori profiles are plotted in Fig. 2.

With the covariance matrix constructed in this way, a significant number of retrievals failed to converge to a solution. A possible reason for this could lie in the specifics of the calculation of the numerical derivatives. We found that this 

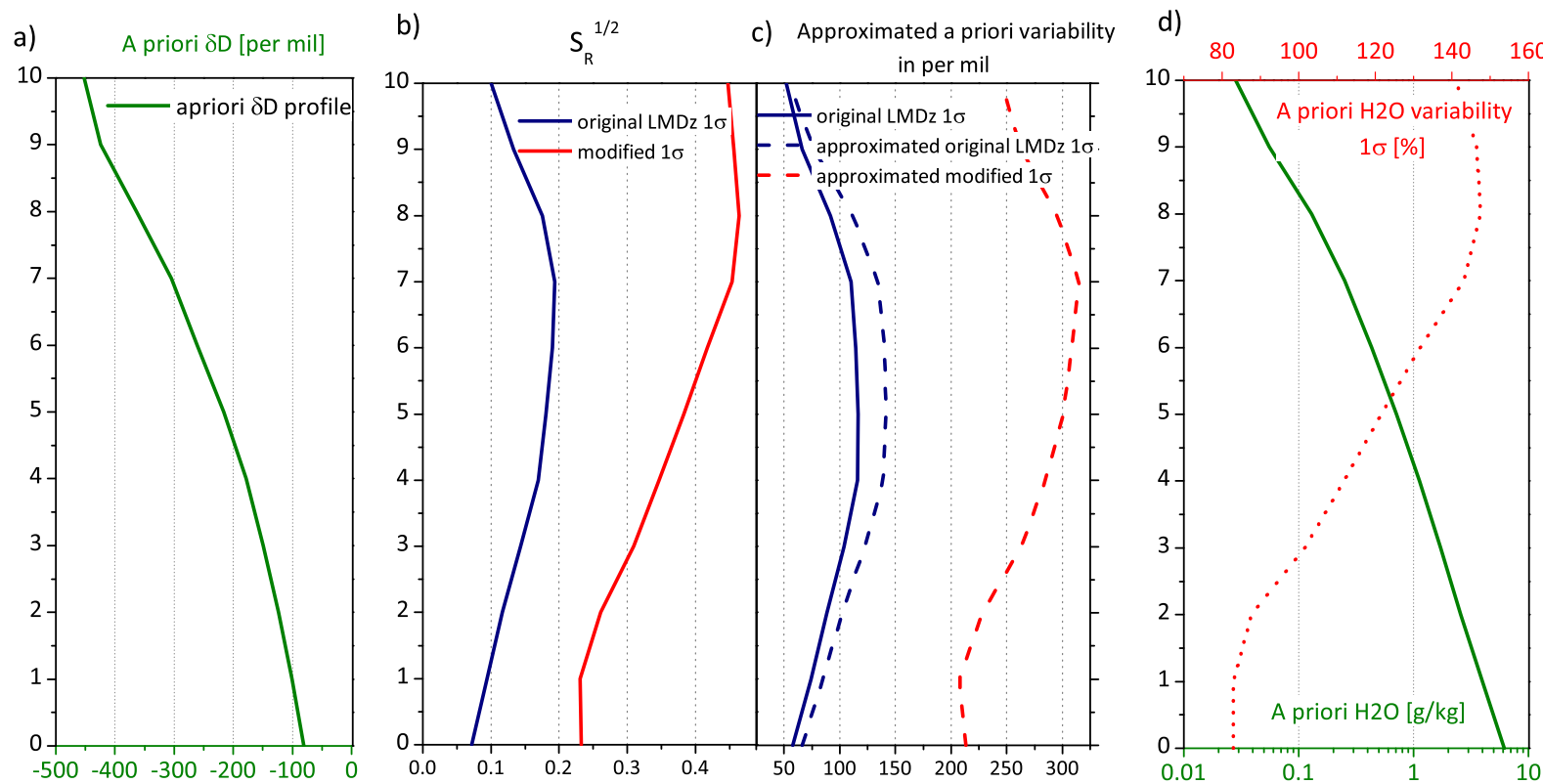

Fig. 2. Description of a priori information. (a) A priori $\delta \mathrm{D}$ profile. (b) $\mathrm{Log}\left(\mathrm{HDO} / \mathrm{H}_{2} \mathrm{O}\right)$ variability $(1 \sigma)$ that originally comes from the $\mathrm{LMDz}$ simulations (blue line) and $\log \left(\mathrm{HDO} / \mathrm{H}_{2} \mathrm{O}\right.$ ) variability $(1 \sigma)$ applied in the retrievals (red line) after modification (see details in the text). (c) Exact variability that originally comes from the model in per mil (blue line) and approximated (dashed blue line). Approximated $1 \sigma$ variability introduced in the retrieval after the modification (dashed red line). (d) A priori $\mathrm{H}_{2} \mathrm{O}$ profile (green line) and its $1 \sigma$ variability expressed in \% (dashed red line).

issue could be solved by lowering the correlation between $\mathrm{HDO}$ and $\mathrm{H}_{2} \mathrm{O}$. This also has the advantage of increasing the a priori variability of $\mathrm{HDO} / \mathrm{H}_{2} \mathrm{O}$ ratio, which could potentially be too constrained in the model. The correlation was lowered by multiplying the inter species correlation elements of $\mathbf{S}_{\mathrm{a}}$ (sub-blocks 3 and 4 of Eq. 7) by an empirical factor that maximizes the number of converging retrievals while maintaining a sufficient constraint on the ratio. Next, we analyze the effect of this modification on the variability that initially comes from the model. To compute the covariance matrix of $\log \left(\mathrm{HDO} / \mathrm{H}_{2} \mathrm{O}\right)$ from our modified $\mathbf{S}_{\mathrm{a}}$ matrix (Eq. 7) we use the following relationship to allow computation of the covariance between differences of random variables:

$$
\begin{aligned}
& \mathbf{S}\left[\mathrm{D}_{1}-\mathrm{H}_{1}, \mathrm{D}_{2}-\mathrm{H}_{2}\right] \\
& \quad=\mathbf{S}\left[\mathrm{D}_{1}, \mathrm{D}_{2}\right]-\mathbf{S}\left[\mathrm{H}_{1}, \mathrm{D}_{2}\right]-\mathbf{S}\left[\mathrm{D}_{1}, \mathrm{H}_{2}\right]+\mathbf{S}\left[\mathrm{H}_{1}, \mathrm{H}_{2}\right],
\end{aligned}
$$

with $\mathrm{H}_{1}, \mathrm{H}_{2}, \mathrm{D}_{1}$ and $\mathrm{D}_{2}$ random variables. Each element of the covariance matrix of the logarithm of the ratio $S\left[\log \left(\mathrm{HDO} / \mathrm{H}_{2} \mathrm{O}\right]=\mathbf{S}_{\mathrm{R}_{i, j}}\right.$ can be written as follows:

$$
\begin{aligned}
\mathbf{S}_{\mathrm{R}_{i, j}} & =\mathbf{S}\left[\log \left(\frac{\mathrm{HDO}_{i}}{\mathrm{H}_{2} \mathrm{O}_{i}}\right), \log \left(\frac{\mathrm{HDO}_{j}}{\mathrm{H}_{2} \mathrm{O}_{j}}\right)\right] \\
& =\mathbf{S}\left[\left(\mathrm{D}_{i}-\mathrm{H}_{i}\right),\left(\mathrm{D}_{j}-\mathrm{H}_{j}\right)\right],
\end{aligned}
$$

with $\mathrm{D}=\log (\mathrm{HDO})$ and $\mathrm{H}=\log \left(\mathrm{H}_{2} \mathrm{O}\right)$. The a priori covariance $\mathbf{S}_{\mathrm{R}}$ can therefore be calculated using Eq. (8) as

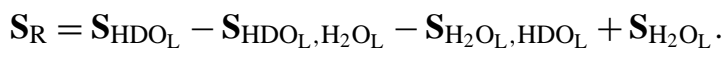

The square root of the diagonal elements of $\mathbf{S}_{\mathrm{R}}$ before and after the modification are plotted in Fig. 2. Note that the square root of the diagonal elements of the $\mathbf{S}_{\mathrm{R}}$ can be approximated by the fractional error:

$$
\Delta \log \left(\frac{\mathrm{HDO}}{\mathrm{H}_{2} \mathrm{O}}\right) \simeq \frac{\Delta \frac{\mathrm{HDO}}{\mathrm{H}_{2} \mathrm{O}}}{\frac{\mathrm{HDO}}{\mathrm{H}_{2} \mathrm{O}}} .
$$

This corresponding variability is also plotted in Fig. $2 \mathrm{c}$ in per mil. The figure shows that the impact of the modification on the $\mathrm{HDO} / \mathrm{H}_{2} \mathrm{O}$ constraint is important. The $\delta \mathrm{D}$ standard deviation that originally comes from $\mathrm{LMDz}$ varies from about 60 per mil in the lower troposphere to about $120 \%$ in the free troposphere; the $\delta \mathrm{D}$ variability introduced in our retrieval varies from about $200 \%$ in the lower troposphere to about $300 \%$ in the mid troposphere. In comparison with the constraint applied in the last version of TES retrievals (Worden et al., 2012) and already existing IASI retrievals (Schneider and Hase, 2011), this constraint is looser. However, we show in the next section that this constraint allows estimating $\delta \mathrm{D}$ with a reasonable error.

\subsection{Sensitivity diagnostic and error estimation}

\subsubsection{Sensitivity of the measurement}

The Jacobians, which are the derivatives of the measurement vector with respect to the state vector elements (Eq. 4), describe the sensitivity of the measurement to changes of the 


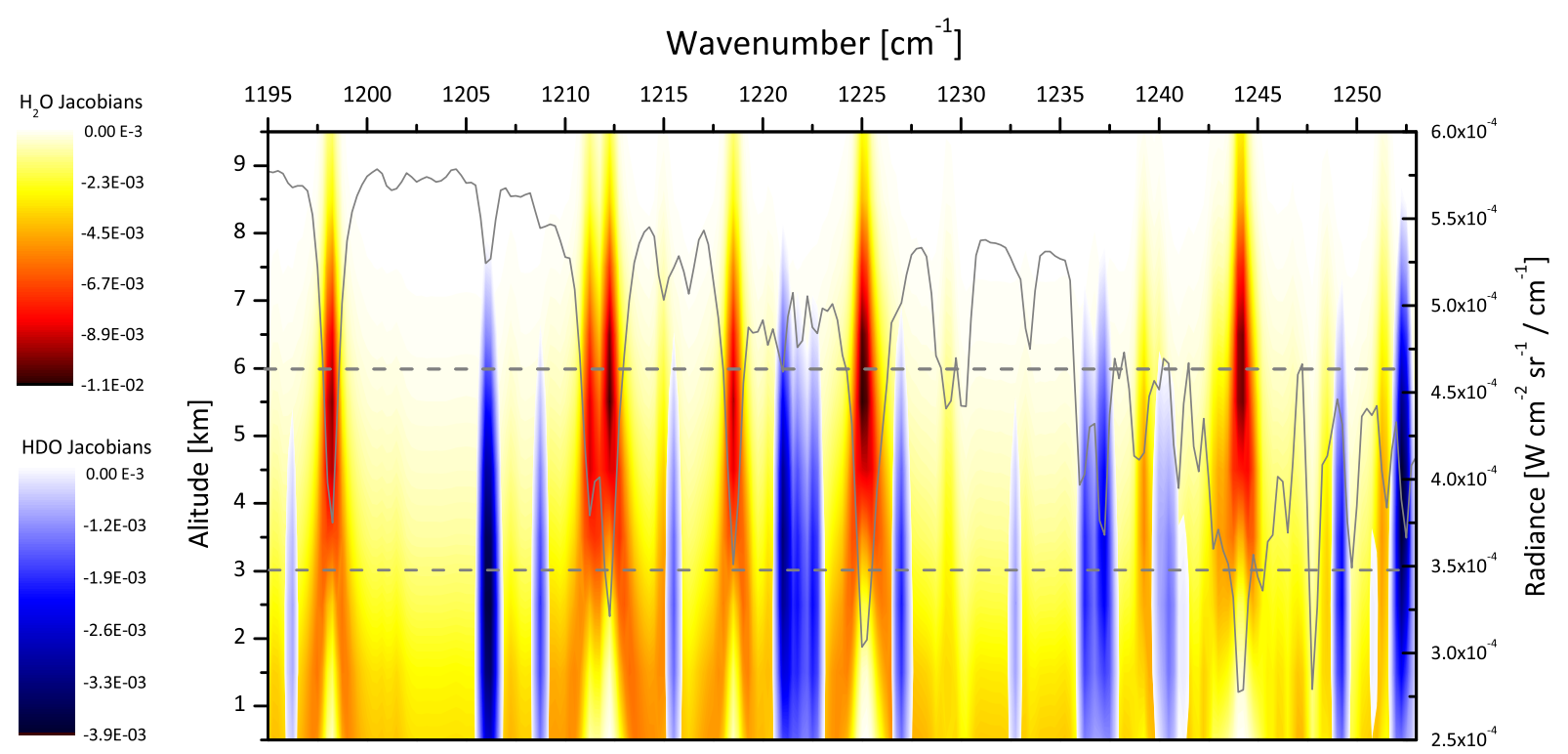

Fig. 3. Jacobians of $\mathrm{H}_{2} \mathrm{O}$ (yellow to dark red) and $\mathrm{HDO}$ (light blue to dark blue) as function of altitude and wavenumber. The smallest derivatives values indicate the maximum sensitivities. The gray dashed lines indicate the altitude of maximum sensitivity for both.

state vector. In Fig. 3, the Jacobians of $\mathrm{HDO}$ and $\mathrm{H}_{2}{ }^{16} \mathrm{O}$ are shown in function of the altitude in the relevant spectral window. The altitudes of maximum sensitivity (most negative derivatives corresponding to the largest derivatives) are different for each isotopologue: for HDO, maximum sensitivity is achieved between 2 and $6 \mathrm{~km}$, while for $\mathrm{H}_{2}{ }^{16} \mathrm{O}$ it is at higher altitudes, between 4 and $7 \mathrm{~km}$, due to saturation at lower altitude at the $\mathrm{H}_{2}{ }^{16} \mathrm{O}$ line centers. For $\mathrm{H}_{2}{ }^{16} \mathrm{O}$, sensitivity below $4 \mathrm{~km}$ remains important but is typically acquired in the selected spectral range in the line wings or between the lines, where continuum absorption dominates.

\subsubsection{Sensitivity of the retrieval}

The averaging kernel matrix is composed of elements that are the derivatives of the estimated state $\hat{\boldsymbol{x}}$ with respect to the state vector $\boldsymbol{x}$ :

$\mathbf{A}=\frac{\partial \hat{\boldsymbol{x}}}{\partial \boldsymbol{x}}$

with in our case $\boldsymbol{x}$ or $\hat{\boldsymbol{x}}$ being expressed in logarithmic space. Averaging kernels are commonly used to evaluate the sensitivity of a retrieval. The matrix can be calculated for total retrieved states vectors $\left(\mathrm{H}_{2} \mathrm{O}, \mathrm{HDO}\right)$ but is not well defined for the calculated $\delta \mathrm{D}$ ratio, as a variation of $\delta \mathrm{D}$ cannot uniquely be translated in variations of $\mathrm{HDO}$ and $\mathrm{H}_{2} \mathrm{O}$ together. Worden et al. (2006) have developed an approach to evaluate the sensitivity of their retrieval to $\mathrm{HDO} / \mathrm{H}_{2} \mathrm{O}$. This approach allows computing the smoothing error covariance matrix for $\mathrm{HDO} / \mathrm{H}_{2} \mathrm{O}$ ratios from the averaging kernel matrices of $\mathrm{HDO}, \mathrm{H}_{2} \mathrm{O}$, as well as the cross term elements of the averaging kernels matrix. The covariance of the smoothing error in its general form (for the complete equations used in the calculation of the smoothing error of $\mathrm{HDO} / \mathrm{H}_{2} \mathrm{O}$ retrieval, see Worden et al., 2006, Sect. 3.2) is expressed as

$\mathbf{S}_{\mathrm{m}}=\left(\mathbf{A}-\mathbf{I}_{\mathrm{n}}\right) \mathbf{S}_{\mathrm{e}}\left(\mathbf{A}-\mathbf{I}_{\mathrm{n}}\right)^{T}$,

with $\mathbf{S}_{\mathrm{e}}$ the covariance matrix of a real ensemble of states generally approximated by the a priori covariance matrix $\mathbf{S}_{\mathrm{a}}$. Equation (13) explicitly includes a vertical sensitivity through the A matrix, and it is obvious that the smoothing error decreases when averaging kernels are close to one and/or if the variability in $\mathbf{S}_{\mathrm{a}}$ is small. We therefore use the ratio of the diagonal elements of the smoothing error (adapted for the joint retrieval) to the diagonal elements of the a priori covariance to identify the altitude at which the retrieval is most sensitive. The results are shown in Fig. 4; they correspond to a mean error profile calculated from all error profiles across a latitudinal band. They reveal a very strong reduction in the uncertainty after the retrieval, over the entire altitude range, but especially between 4 and $6 \mathrm{~km}$.

\subsubsection{Error estimation from forward simulations}

The error of a retrieval can be separated into 3 principal components: (1) the smoothing error, (2) the error due to uncertainties in model parameters, and (3) the error due to the measurement noise. Following this, there are two ways to conduct an error analysis, depending whether one considers the retrieval as an estimate of the true state with an error contribution due to smoothing, or as an estimate of the true state smoothed by the averaging kernels (Rodgers, 2000). The first method requires the covariance matrix of a real ensemble of states to compute the smoothing error. A real ensemble of 


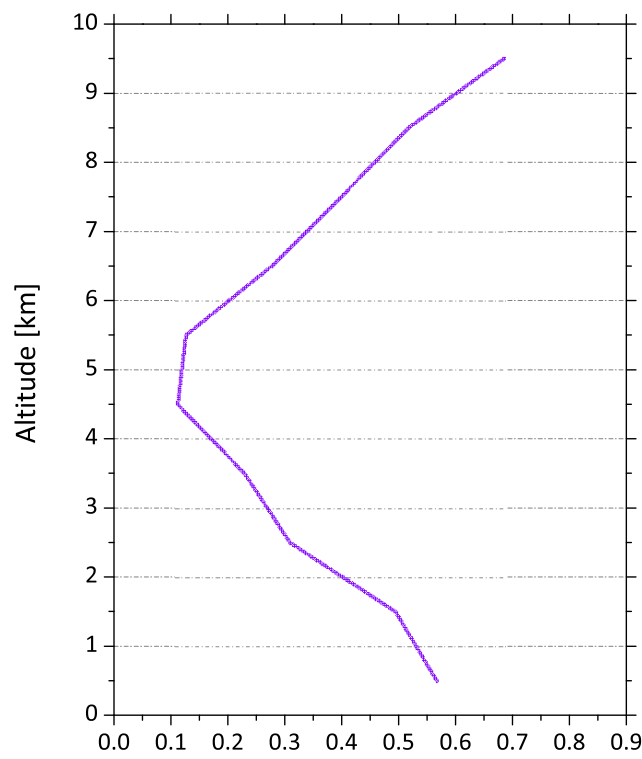

Fig. 4. Ratio of the square root of the diagonal elements of the smoothing error covariance matrix to the square root of the diagonal elements of the a priori covariance matrix.

states is rarely available. In our case it is approximated by the a priori covariance matrix, for which variability was manually increased to aid the retrieval as outlined in Sect. 3.3, and would lead to largely overestimating the smoothing error (see Eq. 13). Here, we therefore estimate errors (2) and (3). To do so, we perform retrievals on a set of simulated IASI spectra (with instrumental noise), representative of different atmospheric conditions. More precisely, 800 spectra have been simulated with temperature and humidity $\left(\mathrm{H}_{2} \mathrm{O}\right.$ and $\left.\mathrm{HDO}\right)$ profiles ranging from standard Arctic profile to tropical standard atmospheres. These various profiles have been extracted from LMDz-iso simulations. We then compared the retrieved profiles with the real ones, smoothed with the averaging kernels to remove the contribution of the smoothing error. The smoothed profiles of water mixing ratios $\left(\boldsymbol{q}_{\mathrm{mAK}}\right)$ are obtained as

$\log \left(\boldsymbol{q}_{\mathrm{mAK}}\right)=\mathbf{A}_{\mathrm{hh}} \cdot \log \left(\boldsymbol{q}_{\mathrm{m}}\right)+\left(\mathbf{I}_{\mathrm{n}}-\mathbf{A}_{\mathrm{hh}}\right) \cdot \log \left(\boldsymbol{q}_{\mathrm{p}}\right)$,

where $\boldsymbol{q}$ is the vector of water mixing ratios for the real (subscript $\mathrm{m}$ ) or the a priori profiles (subscript $\mathrm{p}$ ). $\mathbf{A}_{\mathrm{hh}}$ are the averaging kernels of $\mathrm{H}_{2} \mathrm{O}$. For $\delta \mathrm{D}$, the smoothing also requires involving the cross terms elements of the averaging kernels matrix. Following Worden et al. (2006) and Schneider et al. (2006), the real ratio $\boldsymbol{R}=\mathrm{HDO} / \boldsymbol{q}$ as seen with the sensitivity of our retrieval is

$$
\begin{aligned}
\log ( & \left.\boldsymbol{R}_{\mathrm{mAK}}\right)=\log \left(\boldsymbol{R}_{\mathrm{p}}\right) \\
& +\left[\left(\mathbf{A}_{\mathrm{dd}}-\mathbf{A}_{\mathrm{hd}}\right) \cdot\left(\log \left(\mathrm{HDO}_{\mathrm{m}}\right)-\log \left(\mathrm{HDO}_{\mathrm{p}}\right)\right)\right. \\
& \left.-\left(\mathbf{A}_{\mathrm{hh}}-\mathbf{A}_{\mathrm{dh}}\right) \cdot\left(\log \left(\boldsymbol{q}_{\mathrm{m}}\right)-\log \left(\boldsymbol{q}_{\mathrm{p}}\right)\right)\right] .
\end{aligned}
$$

An extensive study of the different error sources on $\delta \mathrm{D}$ retrievals from IASI (Schneider and Hase, 2011) shows that the two largest contributions to the total error are due to the measurement noise and the uncertainties of the temperature profiles, while other sources of error (spectroscopy, interfering species, surface temperature and emissivity) contribute to less than $4 \%$ o to the total error. For our error estimation we therefore evaluate these two major contributions (we assume that the interference errors are small as we avoid the part of the spectra where major $\mathrm{CH}_{4}$ and $\mathrm{N}_{2} \mathrm{O}$ interferences occur). First, we performed retrievals on simulated spectra with identical temperature profiles in the simulation and in the retrieval. Doing so, there is no uncertainty in the temperature profile and the errors between retrieved and original profiles are only due to the measurement noise. Then, to evaluate the error due to the uncertainties in the temperature profile, we performed the retrievals on simulated spectra with altered temperature profiles. We considered an uncertainty on the temperature of $1.5 \mathrm{~K}$ from 0 to $2 \mathrm{~km}$ and $0.6 \mathrm{~K}$ for the rest of the atmosphere, based on first validation results of the EUMETSAT L2 temperature profiles (Pougatchev et al., 2009). Differences between original and retrieved profiles give the error due to measurement noise and uncertainties in the temperature profiles, which can then be isolated. Figure 5 shows the total error profile expressed as the standard deviation of the difference between original and retrieved profiles and its two main contributions. It shows that the total error is always below $50 \%$ in the altitude range $1-7 \mathrm{~km}$, decreasing to below $40 \%$ between 2 and $5 \mathrm{~km}$. The measurement noise is strongly dominating the error budget throughout the troposphere but especially above $1 \mathrm{~km}$.

The altitude region where the retrieval has the most sensitivity is inferred by the reduction in smoothing error shown in Fig. 4, which indicates a maximum of reduction in error between 3 and $6 \mathrm{~km}$. This range also corresponds to the best compromise in the overlapping of $\mathrm{HDO}$ and $\mathrm{H}_{2}{ }^{16} \mathrm{O}$ maximum measurement sensitivities (see Fig. 3). The total error shown in Fig. 5, which includes contributions from the noise and temperature uncertainties, is reduced between 1 and $5 \mathrm{~km}$. However, the IASI $\mathrm{HDO} / \mathrm{H}_{2} \mathrm{O}$ estimates cannot distinguish the $\mathrm{HDO} / \mathrm{H}_{2} \mathrm{O}$ variability in the lowermost troposphere from that in the middle troposphere.

\subsection{Degree of freedom for signal (DOFS)}

The trace of the averaging kernels matrix, called the degrees of freedom for signal (DOFS), can be used to characterize the information content of the retrieval (Rodgers, 2000). While this metric should be limited by the spectral characteristics of the instrument (radiometric noise and spectral resolution) only, the full capabilities of the instrument are generally underused due to the choice of retrieval setup (mainly the spectral region and a priori information). For example, limiting the number of channels in the retrieval is likely to limit the total information content available in the spectra. The optimal estimation retrieval itself, if over-constrained through the choice of $\mathbf{S}_{\mathrm{a}}$ and $\mathbf{S}_{\epsilon}$, can prevent extracting all the available 
Table 1. Statistics between LMDz-iso simulated and IASI retrieved values for the different datasets presented. $r$ is the correlation coefficient; $\sigma_{\mathrm{LMDz}}$ and $\sigma_{\text {IASI }}$ are the standard deviations of LMDz-iso and IASI, respectively; $R_{\sigma}$ the ratio of standard deviations with $R_{\sigma}=\sigma_{\mathrm{LMDz}} / \sigma_{\mathrm{IASI}} ; E$ is the overall bias $(E=\overline{\mathrm{LMDz}}-\overline{\mathrm{IASI}})$; and $N$ the number of values considered. The standard deviations as the overall bias are expressed in permil and in $\mathrm{g} \mathrm{kg}^{-1}$ for $\delta \mathrm{D}$ and $\mathrm{H}_{2} \mathrm{O}$, respectively.

\begin{tabular}{lccrrrrrrrr}
\hline & & $r$ & $\sigma_{\mathrm{LMDz}}$ & $\sigma_{\mathrm{IASI}}$ & $\sigma_{\text {LMDz }}^{*}$ & $\sigma_{\text {IASI }}^{*}$ & $R_{\sigma}$ & $R_{\sigma^{*}}$ & $E$ & $N$ \\
\hline Izaña & $\delta \mathrm{D}$ & 0.50 & 44.57 & 44.57 & 35.16 & 36.68 & 1.00 & 0.96 & -15.38 & 324 \\
& $\mathrm{H}_{2} \mathrm{O}$ & 0.62 & 0.83 & 1.00 & 0.75 & 0.83 & 0.83 & 0.94 & 0.28 & 324 \\
\hline \multirow{2}{*}{ Darwin } & $\delta \mathrm{D}$ & 0.55 & 29.94 & 33.47 & 27.44 & 31.53 & 0.89 & 0.87 & -1.92 & 267 \\
& $\mathrm{H}_{2} \mathrm{O}$ & 0.69 & 1.35 & 1.43 & 1.30 & 1.38 & 0.94 & 0.94 & -0.36 & 267 \\
\hline \multirow{2}{*}{ Latitudinal Gradient } & $\delta \mathrm{D}$ & 0.83 & 74.02 & 53.46 & $/$ & $/$ & 1.38 & $/$ & -3.41 & 48 \\
& $\mathrm{H}_{2} \mathrm{O}$ & 0.90 & 0.99 & 0.94 & $/$ & $/$ & 1.05 & $/$ & 0.32 & 48 \\
\hline
\end{tabular}

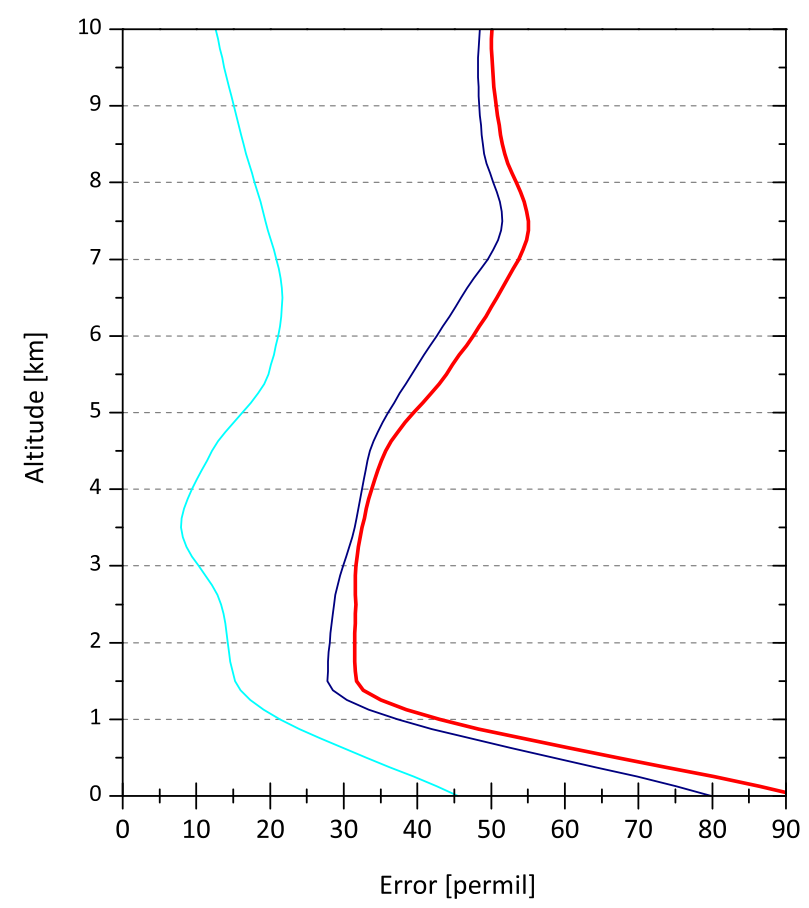

Fig. 5. Total error profile on $\delta \mathrm{D}$ in $\%$ (red line) with the contributions due to the measurement noise (blue line) and to the uncertainties in the temperature profile (cyan line).

information. The sensitivity can also vary with the concentration of the species or due to the temperature profile. Typical HDO and $\mathrm{H}_{2} \mathrm{O}$ DOFS of our retrievals are shown in Fig. 6 for total columns as well as for several partial columns as a function of latitude. We use HDO DOFS here as an approximation for $\delta$ D DOFS. Indeed, while $\delta$ D DOFS should ideally be used to characterize the information content, this is not possible in our case because our retrieval setup is not optimally designed to do so (note that an alternative has recently been proposed by Schneider et al., 2012). Our approximation leads to an overestimation of the true sensitivity (Worden et al., 2012). The total DOFS varies depending on the latitude: between 2.7 and 3.4 for $\mathrm{H}_{2} \mathrm{O}$, and between 1.5 and 1.9 for HDO. Note that the total DOFS for $\mathrm{HDO}$ and $\mathrm{H}_{2} \mathrm{O}$ decreases between $-20^{\circ}$ and $20^{\circ}$, due to a loss of sensitivity in the first retrieval layers, itself resulting from a larger opacity. The DOFS for the 3-6 km layer is pretty constant throughout. Worden et al. (2012) document typical DOFS values from TES retrieval V5 of 5.54 and 1.96 for $\mathrm{H}_{2} \mathrm{O}$ and $\mathrm{HDO}$, respectively. Schneider and Hase (2011) from IASI retrievals at Izaña calculates a DOFS of 3.4 for $\mathrm{H}_{2} \mathrm{O}$ and between 0.7 and 0.8 for $\delta \mathrm{D}$. As we use a smaller retrieval spectral range, the high DOFS found here can only be interpreted as a direct consequence of the choice of a priori covariance matrix with large diagonal elements values (Rodgers, 2000).

\section{Spatio-temporal variability of $\delta \mathrm{D}$ retrievals}

To evaluate the performance of our retrievals on real spectra, we present in this section retrievals at two sites characterized by very different hydrological regimes - namely a subsidence site (Izaña) and a convective site (Darwin) for the year 2010. In addition we provide $\delta$ D variations along a latitudinal gradient from $-60^{\circ}$ to $60^{\circ}$. The evaluation is carried out by comparing the retrieved $\delta \mathrm{D}$ values, and their time and spatial variations with the $\mathrm{LMDz} \mathrm{HDO}$ and $\mathrm{H}_{2} \mathrm{O}$ outputs, smoothed by the averaging kernels of the retrieval (Eqs. 14 and 15). Note that due to the model grid size, the averaging kernels used here correspond to the daily mean averaging kernels of the retrievals contained in the LMDz grid box (grid size of $2.5^{\circ}$ of latitude and $3.75^{\circ}$ of longitude).

To evaluate the differences between observations and model, we first report in Table 1 some statistical diagnostics (Taylor, 2001) for the three studied cases. We report the correlation coefficient $(r)$, the standard deviations of the LMDz-iso and IASI datasets $\left(\sigma_{\mathrm{LMDz}}\right.$ and $\left.\sigma_{\mathrm{IASI}}\right)$, the ratio of their standard deviations $\left(R_{\sigma}=\sigma_{\mathrm{LMDz}} / \sigma_{\mathrm{IASI}}\right)$, the overall bias $(E)$, and $N$, the number of observations. These statistics are used to support the discussion in the next two subsections. 

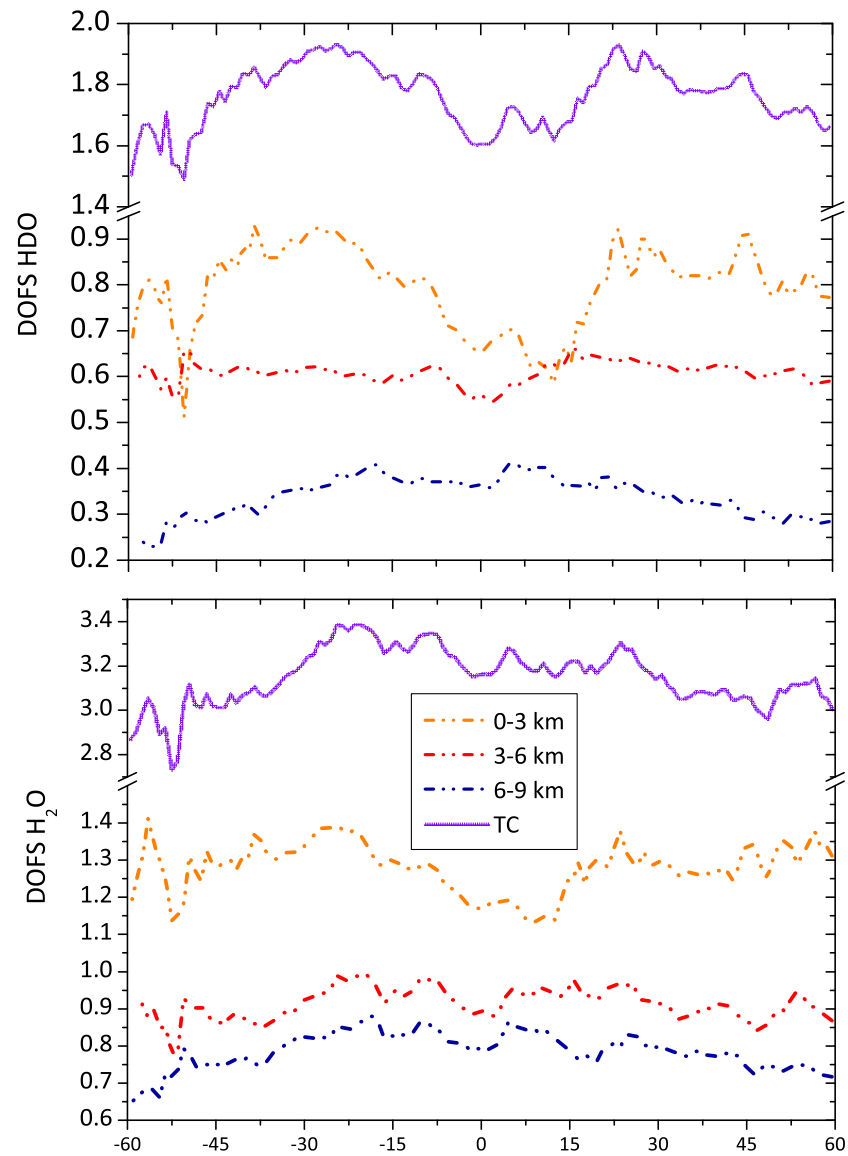

Fig. 6. DOFS for total columns (purple line), and for the partial columns 0-3 km (dashed orange line), 3-6 km (dashed red line), and 6-9 km (dashed blue line). For HDO (top panel) and $\mathrm{H}_{2} \mathrm{O}$ (bottom panel).

For this comparison, we removed retrievals with a RMS of the residual of the fit that exceeds the measurement noise $\sigma_{\epsilon}$ by a factor of two or more.

\subsection{Annual and day-to-day variability at Izaña and Darwin}

The principal advantage of IASI over other satellite sounders measuring $\delta \mathrm{D}$ is its spatial and temporal coverage. Indeed, IASI provides global coverage twice a day, which allows studying day-to-day variability of isotopic distributions. This is not possible with TES and SCIAMACHY instruments as they need several days to achieve global coverage.

Retrieved $\delta \mathrm{D}$ and $\mathrm{H}_{2} \mathrm{O}$ time series for the Darwin and Izaña sites are shown respectively in Figs. 7 and 8 together with LMDz-iso simulations (blue crosses). The studied zones extend from $128^{\circ} \mathrm{E}$ to $133^{\circ} \mathrm{E}, 14^{\circ} \mathrm{S}$ to $10^{\circ} \mathrm{S}$ for Darwin, and from $18.5^{\circ} \mathrm{W}$ to $14.5^{\circ} \mathrm{W}, 26^{\circ} \mathrm{N}$ to $30^{\circ} \mathrm{N}$ for Izaña. Plotted values are integrated $\delta \mathrm{D}$ values for the 3-6 km layer. Dailyaveraged retrieved values (full red circles) have been spatially averaged over the model grid box. A 30 days smooth- ing filter applied on modeled (thick blue line) and observed (thick red line) values is also plotted to highlight the underlying seasonal and intra-seasonal pattern. We discuss hereafter the seasonal variations and then the short term variations, which strongly overlap the seasonal cycle.

\subsubsection{Seasonal variability}

Darwin is a tropical site with two distinct seasons: a dry season, from May to October (Austral winter), and a wet season from November to April (Austral summer) characterized by cloudy and rainy conditions caused by large scale convective processes. Figure 7, which gives the 2010 time series of $\delta \mathrm{D}$, shows well-marked seasonal differences $(80 \%$ amplitude) with lower retrieved $\delta \mathrm{D}$ values in winter (a minimum of $-200 \%$ in June) and with high values in summer (maximum of $-120 \%$ in February). This is in excellent agreement with LMDz-iso, which shows a $\pm 95 \%$ amplitude with a similar maximum in February $(-130 \%$ o $)$ and a minimum in June $(-225 \%$ o). The comparison with $\mathrm{LMDz}$ is particularly remarkable considering the very strong similarity in the timing and relative variations for both $\mathrm{H}_{2} \mathrm{O}$ and $\delta \mathrm{D}$. At Darwin, the isotopic composition is mainly sensitive to two overlapping effects: (1) a seasonality effect with low $\delta \mathrm{D}$ values in austral winter when subsidence is important, in that case $\mathrm{H}_{2} \mathrm{O}$ and $\delta \mathrm{D}$ will be correlated; and (2) an effect due to the convection that contributes to deplete the air mass in HDO, in that case $\delta \mathrm{D}$ and $\mathrm{H}_{2} \mathrm{O}$ trends will be anti-correlated. This second effect is clearly visible on the Darwin time series in January-mid February where $\mathrm{H}_{2} \mathrm{O}$ reaches a maximum while $\delta \mathrm{D}$ reaches a minimum.

Izaña, located in the northern Atlantic Ocean at subtropical latitudes, is characteristic of a subsidence zone with a very dry climate. The time series for Izaña is shown in Fig. 8. A seasonal cycle is clearly identifiable with low $\delta \mathrm{D}$ values in winter (min values of $-250 \%$ ), and high values in summer (max values of $-150 \%$ ). The general agreement between IASI and LMDz is good, but contrary to what we observed at Darwin, there are some noticeable differences in the seasonal and intra-seasonal variations. In particular, the seasonality (difference between summer months and winter months) retrieved with IASI is larger than LMDz: in winter LMDz simulates higher $\delta \mathrm{D}$ values than IASI, and in summer model simulations are lower. In the annual mean this translates to a $-15 \%$ bias of IASI compared to the model. While these differences in $\delta \mathrm{D}$ could be due in part to the retrievals, we believe that they essentially come from the model, which has been shown before to underestimate the $\delta \mathrm{D}$ seasonality in the subtropics (Risi et al., 2012b). Note that the differences do not apply to $\mathrm{H}_{2} \mathrm{O}$ (bottom panel of Fig. 8), for which observations and simulations are in very good agreement during the winter months, but where IASI retrievals are systematically higher than the model from May to the end of September. In June, the strong increase of $\delta \mathrm{D}$, followed by 

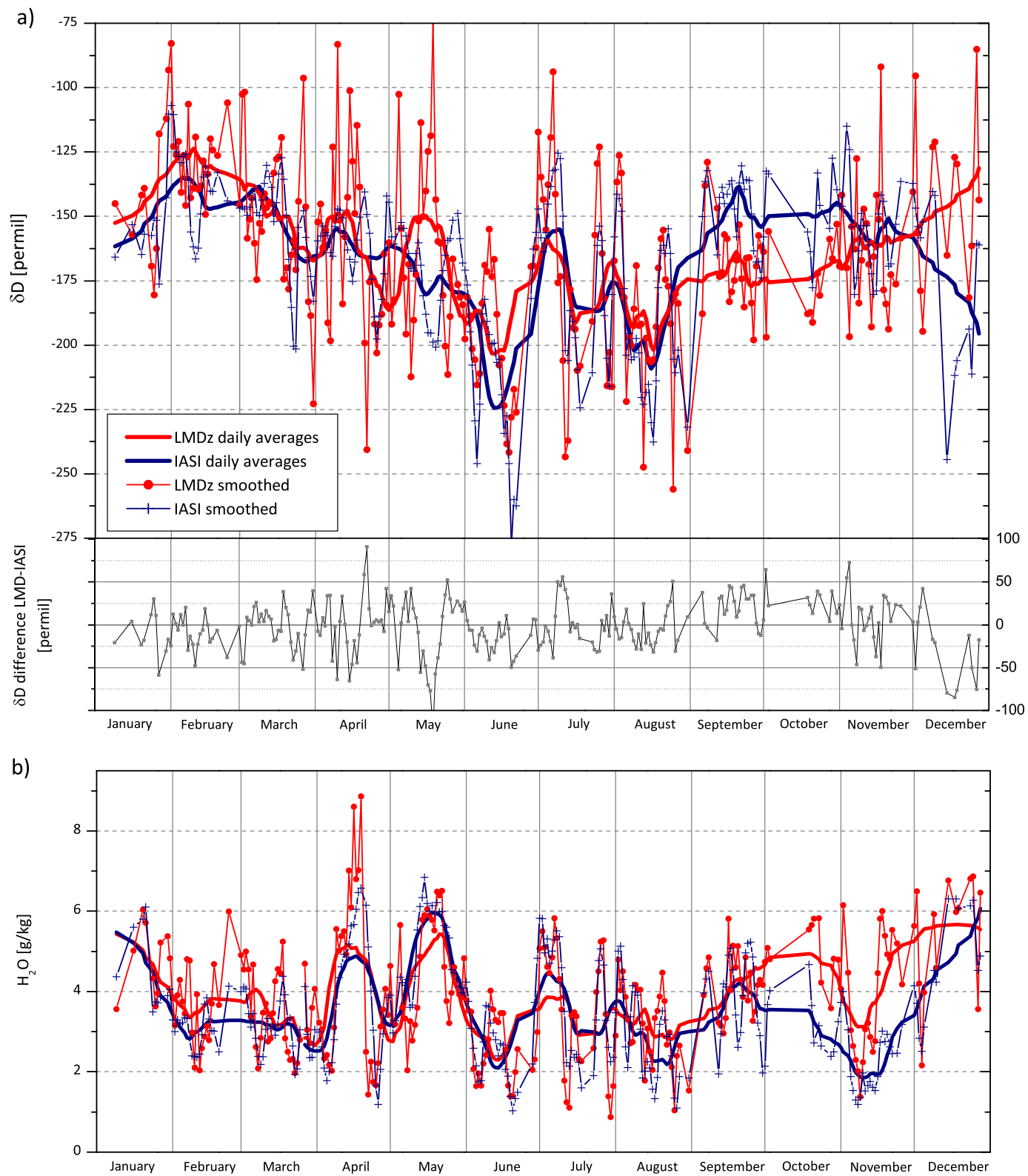

Fig. 7. Time series at the Darwin site for the year 2010 for the 3-6 km layer. (a) Top pannel: IASI $\delta$ D daily averages (red circles and line) are compared to corresponding LMDz-iso simulations (blue crosses and line). A Savitzky-Golay smoothing filter has been applied (thick lines) to highlight seasonal and intra-seasonal pattern. (b) Same as (a) but for specific humidity in $\mathrm{g} \mathrm{kg}^{-1}$.

the increase of water amount, probably indicates a decrease in subsidence.

\subsubsection{Short term variability}

Figure 9 is provided in support of Figs. 7 and 8 to evaluate the variability of the daily mean variations of $\delta \mathrm{D}$. Because a direct computation of the standard deviation of the daily averages do not only reflect the day-to-day variability but also the variability induced by the seasonal cycle, it is important to remove the signal due to seasonal variations in order to analyze the short term variability. This has been done by fitting a seasonal trend through the data points, which was subsequently subtracted. Fourier series, which integrate sum of sine and cosine functions, have been used to fit the seasonal behavior (dotted lines in Fig. 9). As the model and the IASI time series exhibit slightly different seasonal behavior (see previous section), the fitted curve is different for each. The $\delta \mathrm{D}$ time series at Izaña and Darwin are plotted in Fig. 9 with the fitted trend for IASI (top panel) and LMDz (middle panel). The differences for LMDz and IASI are plotted on the bottom panel 

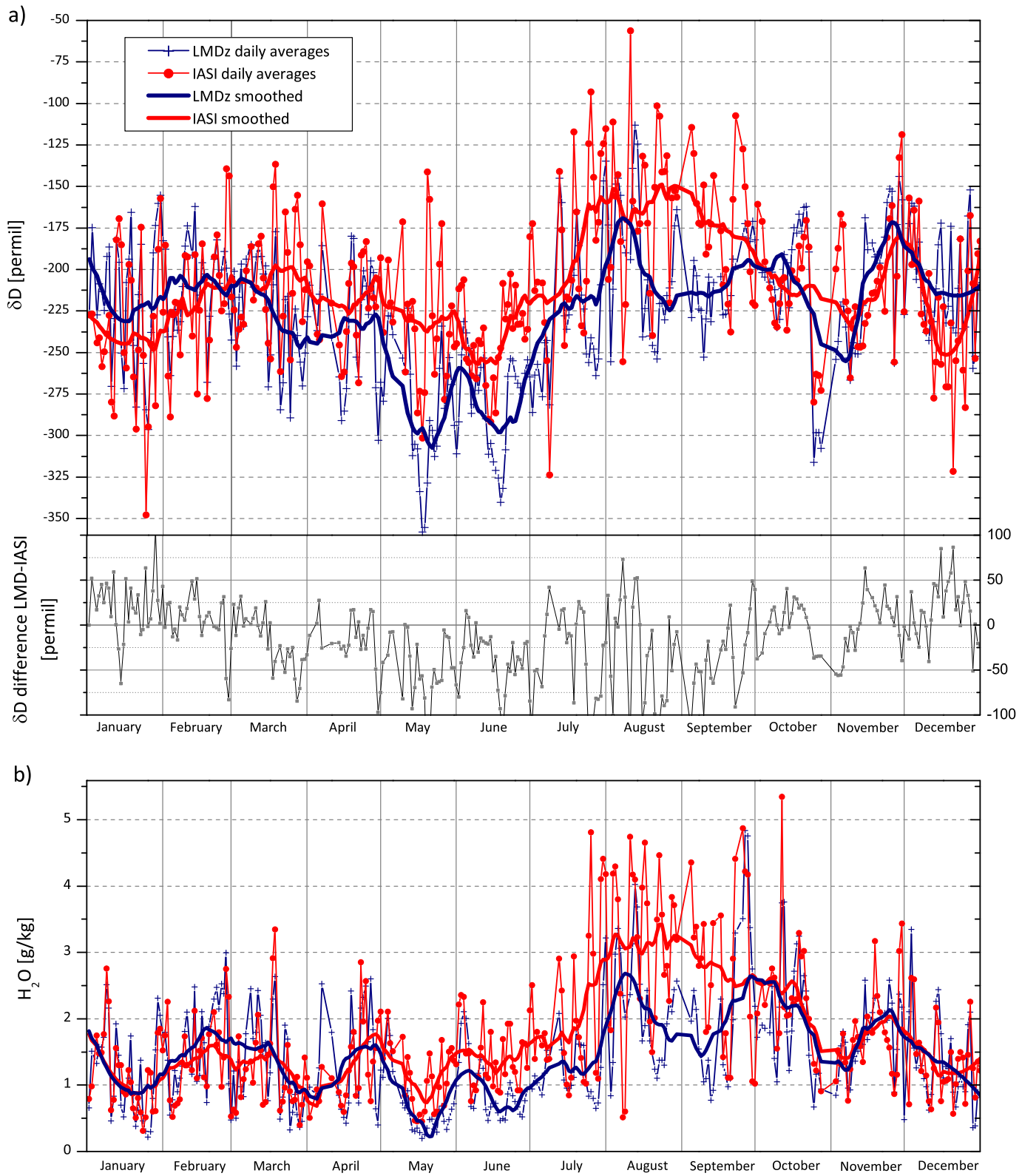

Fig. 8. Same as Fig. 7 but for the Izaña site.

and compared. The standard deviations computed on the detrended signals are reported in Table $1\left(\sigma^{*}\right)$.

Figure 9 reveals strong day-to-day variations at the two locations (this is also seen in Figs. 7, 8 on top of the broad seasonal and intra-seasonal variations). For instance, in a few days $\delta \mathrm{D}$ can vary by $100 \%$ (e.g. at Darwin in June or Izaña in October), which is similar to the amplitude of the seasonal cycle. A remarkable result of this preliminary comparison comes from the general excellent agreement between IASI and model $\delta \mathrm{D}$ values on a daily basis. At Darwin the differences between LMDz-iso and IASI (middle panel of Fig. 7) are below $50 \%$ ( $91 \%$ of the points) and below $25 \%$ (64\% of the points). We note however a tendency of IASI to have larger variability (for example in April-May), as further discussed below. The bias of annual mean is below $2 \%$.

At Izaña, the differences in Fig. 8 are larger and vary seasonally, which is due to the seasonal bias already highlighted in Sect. 4.1.1. However, this disappears after subtraction of the seasonal trend and we see that LMDz-iso and IASI tend to agree better (ratio of standard deviation of 0.96 , see Table 1) than at Darwin, where the variability in the retrieved value $(31.5 \%$ ) is higher by $4 \%$ o than that from the model $(27.4 \%$ ) . This is also seen from Fig. 10, where retrieved $\delta \mathrm{D}$ (daily averaged value in the grid box) are plotted versus 

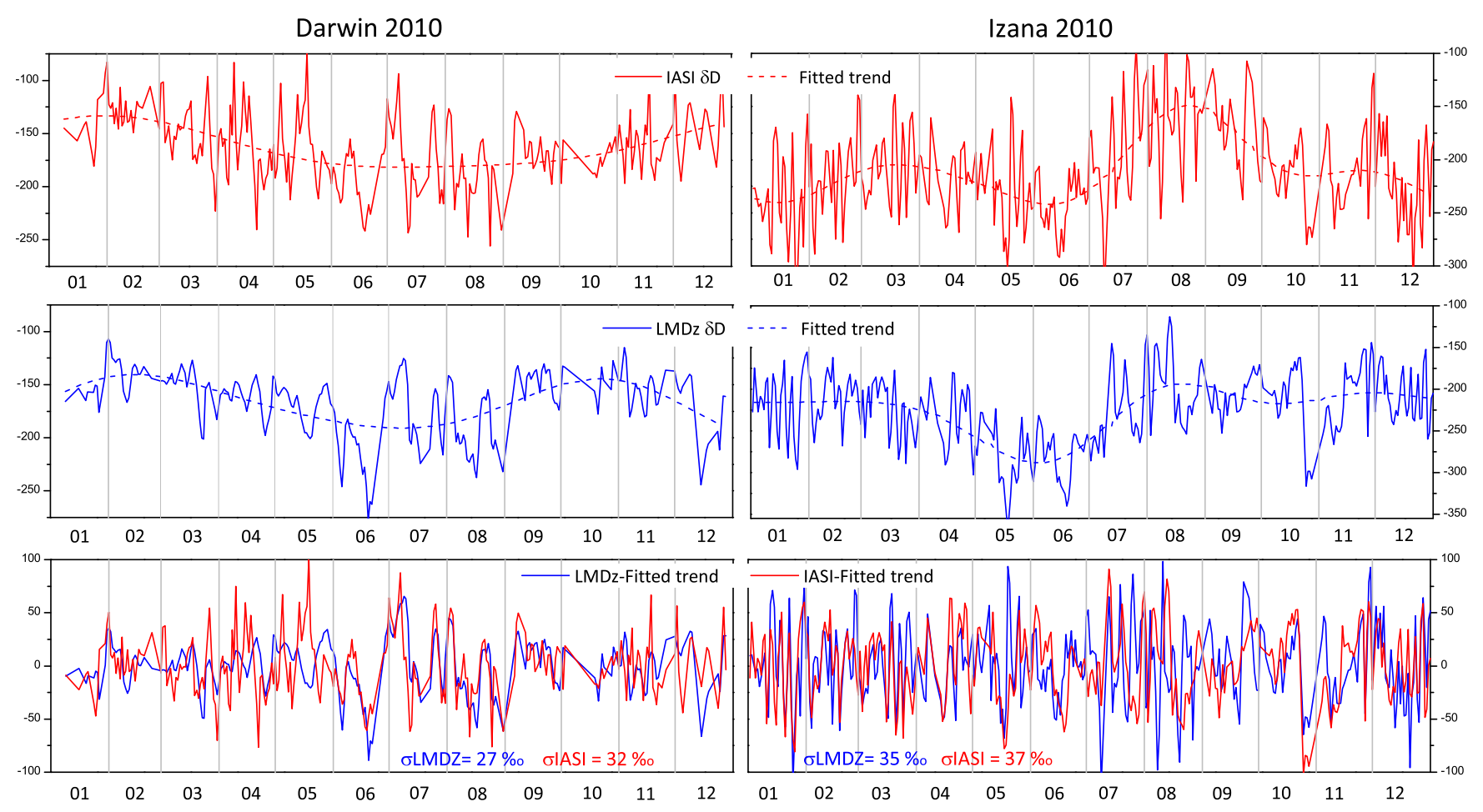

Fig. 9. $\delta$ D time series at Darwin and Izaña retrieved from IASI (top) and simulated by LMDz (middle). The dotted lines are fitted Fourier functions isolating the broad seasonal component of the variations. The bottom panels show the detrended time series obtained by subtracting the Fourier functions from the raw data.

model $\delta \mathrm{D}$ values. This figure also allows for a visualization of the correlation pattern between the two different data sets. At Izaña, we find a correlation coefficient of 0.5 (see also Table 1) when taking all observations into account. If we only consider the IASI measurements for which the daily variability in the grid box is below $35 \%$, the correlation coefficient increases to 0.64 with a slope still close to 1 . At Darwin this effect is not observed; the slope of 1.22 indicates a larger amplitude of the variations of IASI as compared to the model (similar indication than the standard deviations ratio). The correlation coefficient is also relatively significant $(0.55)$ here (Fig. 10 and Table 1).

\subsection{Spatial variability along a latitudinal gradient}

In addition to the temporal variations, we have examined the ability of IASI to capture the spatial variability of $\delta \mathrm{D}$ by considering a latitudinal band from $-60^{\circ}$ to $60^{\circ}$. Figure 11 shows the $\delta \mathrm{D}$ and $\mathrm{H}_{2} \mathrm{O}$ latitudinal distributions representative of the 3-6 km layer averaged on LMDz-iso grid boxes (from $-30^{\circ}$ to $-25^{\circ}$ in longitude above ocean surfaces) for the first 15 days of January 2010. As expected, the retrieved $\delta \mathrm{D}$ are largest near the Equator (mean value of $-140 \%$ ) and decrease polewards to reach a minimum value of $-350 \%$ at $56^{\circ} \mathrm{S}$ (gradient of $-210 \%$ ). Local maxima are observed in the subtropics for both $\mathrm{H}_{2} \mathrm{O}$ and $\delta \mathrm{D}$ distributions but with a significant phase shift, with $\delta \mathrm{D}$ maxima being localized at higher latitudes than $\mathrm{H}_{2} \mathrm{O}$. This can be explained by the fact that at high and mid latitudes, isotopic composition follows a Rayleigh type distillation, while at subtropical latitudes, the isotopic composition is sensitive to mixing processes, which will lead to an enrichment of the air parcel for a same water amount (Galewsky and Hurley, 2010). In the tropics, convection contributes to the depletion of air masses in the heavier isotopologues. These processes are responsible for the smoother behavior of $\delta \mathrm{D}$ compared to $\mathrm{H}_{2} \mathrm{O}$.

The retrieved values are in very good agreement with modeled values for water vapour (correlation coefficient of 0.90 , ratio of standard deviations of 1.05 and a moist bias of $\left.0.32 \mathrm{~g} \mathrm{~kg}^{-1}\right)$. The observed variations are in phase with the simulated ones. The only noticeable differences are the lower water concentration simulated by $\mathrm{LMDz}$ at the Equator and the higher concentrations simulated in the southern subtropics.

The comparison of the $\delta \mathrm{D}$ gradients is also very good on a global scale, with a correlation coefficient of 0.83 . However, large differences occur in the magnitude of the variations with a ratio of standard deviations of 1.38 (LMDz has a larger standard deviation $(74.02 \%$ ) than IASI $(53.46 \%$ )). The timing of the variations is also quite good. The major differences occur in subtropical regions where LMDz systematically simulates higher $\delta \mathrm{D}$ values than IASI and where correspondence between the LMDz and IASI timing is not 

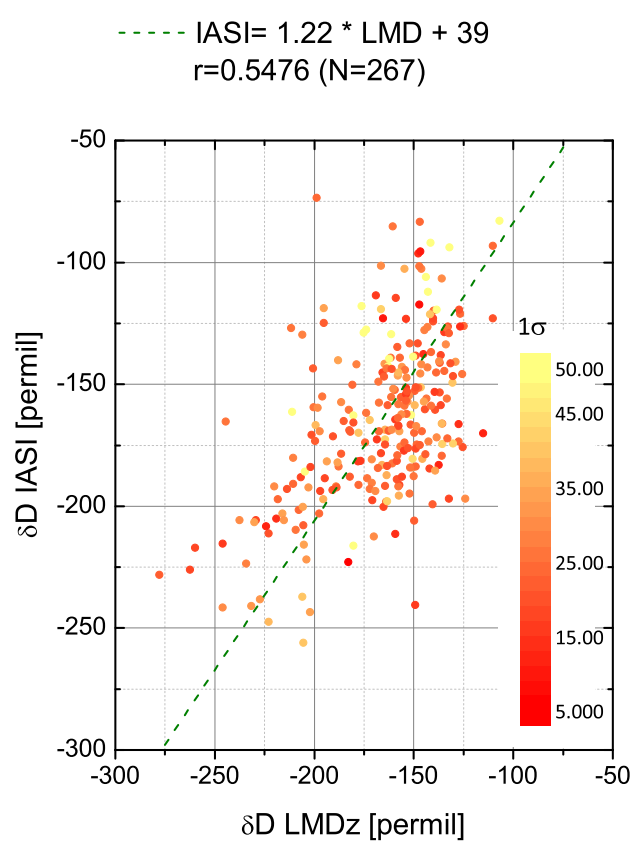

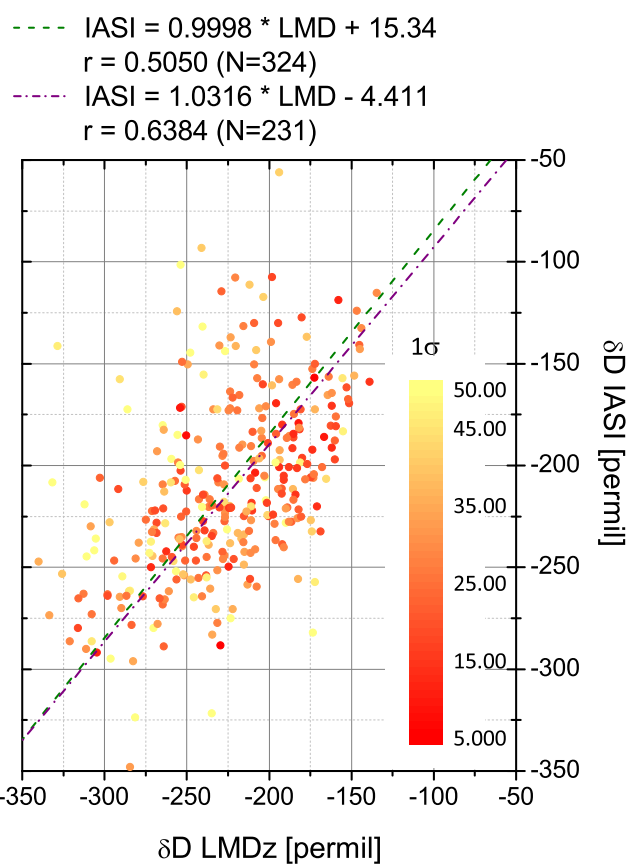

Fig. 10. Scatter plots of daily averaged $\delta$ D IASI observations versus LMDz-iso simulations for Izaña site (right) and Darwin site (left). The color scale indicates the daily variability $(1 \sigma)$ of IASI retrieved values in the model grid box. The dashed and the dashed-dotted lines are reduced major axis regressions on all points (dashed green lines) and, for Izaña, on points with a $1 \sigma$ variability in the model grid box lower than 35. In the case of Izaña, there is clear increase of the correlation coefficient (from 0.5 to 0.64 ) when considering only $\delta \mathrm{D}$ averages with a certain variability threshold (averages with a daily variability inferior to $35 \%$, dashed-dotted violet line). The line equations, the correlation coefficient and the number of coincident values are given above the figures.
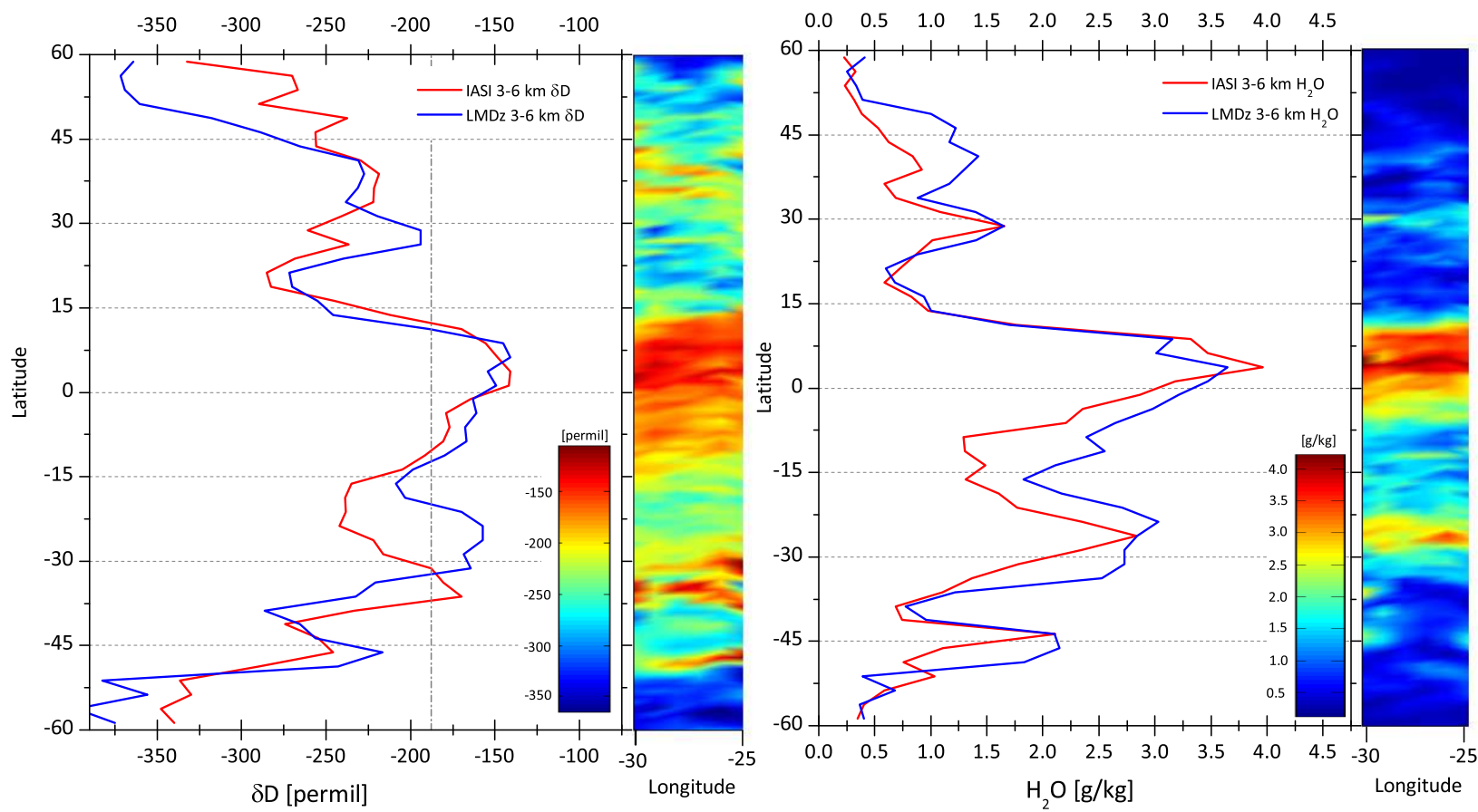

Fig. 11. Latitudinal distribution of $\delta \mathrm{D}$ (left) with $\delta \mathrm{D}$ a priori (gray dashed-dotted line) and $\mathrm{H}_{2} \mathrm{O}$ (right) retrieved with IASI (red) and simulated by LMDz-iso (blue). $\delta$ D retrievals, representative of the 3-6 km layer, have been averaged on the first 15 days of January 2010 and on the LMDz-iso grid boxes. The corresponding spatial distributions of IASI retrievals are mapped besides the latitudinal gradients. 
good. Noticeable differences also appear between $45^{\circ}$ and $60^{\circ}$ where $\mathrm{LMDz}$ values are much lower than the retrieved values, differences reaching $100 \%$ around $54^{\circ}$. In addition to the underestimation of the seasonality at subtropical latitudes, Risi et al. (2012b) have identified an underestimation of the latitudinal gradient (zonal annual mean) and in particular a pronounced high bias in $\delta \mathrm{D}$ at subtropical latitudes as robust features of the model. While we do not observe the underestimation of latitudinal gradient by LMDz, our comparison tends to confirm a misrepresentation of the processes affecting $\delta \mathrm{D}$ in the subtropics. A detailed study of the IASI to model differences is beyond the scope of the present paper and will be the subject of forthcoming analyses.

\section{Conclusions}

We have described a new joint retrieval methodology for $\mathrm{H}_{2} \mathrm{O}$ and $\mathrm{HDO}$ from IASI radiances spectra. Based on optimal estimation, the method is different from our previous work in that it constrains the retrievals by explicitly introducing correlations in the concentrations of the two species inside the a priori covariance matrix $\mathbf{S}_{\mathrm{a}}$. This matrix was built from a global set of daily vertical profiles from the LMDziso GCM representative of the whole year. It therefore shows large variability around the a priori (the average profile of $\mathrm{H}_{2} \mathrm{O}$ and HDO). The $\mathbf{S}_{\mathrm{a}}$ matrix was slightly modified to decrease the modeled correlations between the two species. The spectral range for the retrievals was set to 1193 to $1253 \mathrm{~cm}^{-1}$ with a gap between 1223 and $1251 \mathrm{~cm}^{-1}$. With these settings, we show that IASI provides maximum sensitivity simultaneously to $\mathrm{HDO}$ and $\mathrm{H}_{2} \mathrm{O}$ in the free troposphere with errors on the retrieved $\delta \mathrm{D}$ vertical profiles lower than $40 \%$ o between 2 and $5 \mathrm{~km}$. For an individual retrieval, the standard deviation on $\delta \mathrm{D}$ in the 3-6 km layer is $38 \%$ and was shown to be dominated by the measurement noise.

The seasonal variability of IASI retrieved $\delta \mathrm{D}$ values was examined at two locations for the year 2010, and compared to that of the LMDz-iso model. We found a general excellent agreement in the magnitude of the seasonal pattern, although local differences exist. While at Izaña a clear seasonal bias has been identified (overall bias of $15 \%$ ), the bias at Darwin is insignificant $(<2 \%)$. Beyond the seasonal cycle, we have demonstrated the good performance of IASI to capture shortterm variations of $\delta \mathrm{D}$ (e.g. day-to-day variations) despite significant differences in the amplitude of variations estimated between the model and the measurements at Darwin. It is worthwhile mentioning that IASI is currently the only satellite sounder that allows monitoring $\delta \mathrm{D}$ on a daily basis. Finally, we have investigated the performance of the retrievals by analyzing the $\delta \mathrm{D}$ results for a $5^{\circ}$ wide longitude band from $-60^{\circ} \mathrm{S}$ to $60^{\circ} \mathrm{N}$ for the first 15 days of January. We show that the retrieved values are in very good agreement with the model (correlation coefficient of 0.83), even though noticeable differences occur. These are a significant deviation be- tween LMDz and IASI at subtropical latitudes and also lower $\delta \mathrm{D}$ values simulated beyond the $45^{\circ}$ latitudes. While differences highlighted in this study could still be due to retrieval issues, they confirm previously documented shortcomings of the model.

More generally, results presented here highlight further the exceptional potential of IASI to contribute to the understanding of hydrological processes.

Acknowledgements. IASI has been developed and built under the responsibility of the Centre National d'Etudes Spatiales (CNES, France). It is flown onboard the MetOp satellites as part of the EUMETSAT Polar System. The IASI L1 data are received through the EUMETCast near real time data distribution service. The research in Belgium was funded by the "Communauté Française de Belgique - Actions de Recherche Concertées", the Fonds National de la Recherche Scientifique (FRS-FNRS F.4511.08), the Belgian Science Policy Office and the European Space Agency (ESAProdex C90-327). L. Clarisse and P.-F. Coheur are respectively Postdoctoral Researcher (Chargé de Recherches) and Research Associate (Chercheur Qualifié) with F.R.S.-FNRS. C. Clerbaux is grateful to CNES for scientific collaboration and financial support. The authors would like to thank J. Worden and M. Schneider for their comments during the review process which greatly improved this manuscript.

Edited by: G. Stiller

\section{References}

Berkelhammer, M., Risi, C., Kurita, N., and Noone, D. C.: The moisture source sequence for the Madden-Julian Oscillation as derived from satellite retrievals of $\mathrm{HDO}$ and $\mathrm{H}_{2} \mathrm{O}$, J. Geophys. Res., 117, D03106, doi:10.1029/2011JD016803, 2012.

Bony, S., Colman, R., Kattsov, V., Allan, R., Bretherton, C., Dufresne, J., Hall, A., Hallegatte, S., Holland, M., Ingram, V., Randall, D., Soden, B., Tselioudis, G., and Webb, M.: How Well Do We Understand and Evaluate Climate Change Feedback Processes?, J. Climate, 19, 3445-3482, 2006.

Clerbaux, C., Boynard, A., Clarisse, L., George, M., Hadji-Lazaro, J., Herbin, H., Hurtmans, D., Pommier, M., Razavi, A., Turquety, S., Wespes, C., and Coheur, P. F.: Monitoring of atmospheric composition using the thermal infrared IASI/MetOp sounder, Atmos. Chem. Phys., 9, 6041-6054, doi:10.5194/acp-9-6041-2009, 2009.

Craig, H.: Isotopic Variations in Meteoric Waters, Science, 133, 1702-1703, doi:10.1126/science.133.3465.1702, 1961.

Ehhalt, D. H.: Vertical profiles of HTO, HDO, and $\mathrm{H}_{2} \mathrm{O}$ in the Troposphere, NCAR-TN/STR-100, Natl. Cent. for Atmos. Res., Boulder, Colo., 1974.

Frankenberg, C., Yoshimura, K., Warneke, T., Aben, I., Butz, A., Deutscher, N., Griffith, D., Hase, F., Notholt, J., Schneider, M., Schrijver, H., and Rockmann, T.: Dynamic Processes Governing Lower-Tropospheric $\mathrm{HDO} / \mathrm{H}_{2} \mathrm{O}$ Ratios as Observed from Space and Ground, Science, 325, 1374-1377, doi:10.1126/science.1173791, 2009. 
Frierson, D. M. W.: The Dynamics of Idealized Convection Schemes and Their Effect on the Zonally Averaged Tropical Circulation, J. Atmos. Sci., 64, 1959-1976, doi:10.1175/JAS3935.1, 2007.

Galewsky, J. and Hurley, J. V.: An advection-condensation model for subtropical water vapor isotopic ratios, J. Geophys. Res., 115, D16116, doi:10.1029/2009JD013651, 2010.

Galewsky, J., Strong, M., and Sharp, Z. D.: Measurements of water vapor D/H ratios from Mauna Kea, Hawaii, and implications for subtropical humidity dynamics, Geophys. Res. Lett., 34, L22808, doi:10.1029/2007GL031330, 2007.

Galewsky, J., Rella, C., Sharp, Z., Samuels, K., and Ward, D.: Surface measurements of upper tropospheric water vapor isotopic composition on the Chajnantor Plateau, Chile, Geophys. Res. Lett., 38, L17803, doi:10.1029/2011GL048557, 2011.

Herbin, H., Hurtmans, D., Clerbaux, C., Clarisse, L., and Coheur, P.-F.: $\mathrm{H}_{2}^{16} \mathrm{O}$ and HDO measurements with IASI/MetOp, Atmos. Chem. Phys., 9, 9267-9290, doi:10.5194/acpd-9-92672009, 2009.

Hilton, F., Armante, R., August, T., Barnet, C., Bouchard, A., Camy-Peyret, C., Capelle, V., Clarisse, L., Clerbaux, C., Coheur, P.-F., Collard, A., Crevoisier, C., Dufour, G., Edwards, D., Faijan, F., Fourrié, N., Gambacorta, A., Goldberg, M., Guidard, V., Hurtmans, D., Illingworth, S., Jacquinet-Husson, N., Kerzenmacher, T., Klaes, D., Lavanant, L., Masiello, G., Matricardi, M., McNally, A., Newman, S., Pavelin, E., Payan, S., Péquignot, E., Peyridieu, S., Phulpin, T., Remedios, J., Schlüssel, P., Serio, C., Strow, L., Stubenrauch, C., Taylor, J., Tobin, D., Wolf, W., and Zhou, D.: Hyperspectral Earth Observation from IASI: Five Years of Accomplishments, B. Am. Meteor. Soc., 93, 347-370, doi:10.1175/BAMS-D-11-00027.1, 2012.

Hurtmans, D., Coheur, P.-F., Wespes, C., Clarisse, L., Scharf, O., Clerbaux, C., Hadji-Lazaro, J., George, M., and Turquety, S.: FORLI radiative transfer and retrieval code for IASI, J. Quant. Spectrosc. Ra., 113, 1391-1408, doi:10.1016/j.jqsrt.2012.02.036, 2012.

Johnson, L. R., Sharp, Z. D., Galewsky, J., Strong, M., Van Pelt, A. D., Dong, F., and Noone, D.: Hydrogen isotope correction for laser instrument measurement bias at low water vapor concentration using conventional isotope analyses: application to measurements from Mauna Loa Observatory, Hawaii, Rapid Commun. Mass Sp., 25, 608-616, doi:10.1002/rcm.4894, 2011.

Kang, S. M., Held, I. M., Frierson, D. M. W., and Zhao, M.: The Response of the ITCZ to Extratropical Thermal Forcing: Idealized Slab-Ocean Experiments with a GCM, J. Climate, 21, 35213532, doi:10.1175/2007JCLI2146.1, 2008.

Kiehl, J. T. and Trenberth, K. E.: Earth's Annual Global Mean Energy Budget, Bull. Amer. Meteor. Soc., 78, 197-208, doi:10.1175/1520-0477(1997)078<0197:EAGMEB > 2.0.CO;2, 1997.

Kurita, N., Noone, D., Risi, C., Schmidt, G. A., Yamada, H., and Yoneyama, K.: Intraseasonal isotopic variation associated with the Madden-Julian Oscillation, J. Geophys. Res., 116, D24101, doi:10.1029/2010JD015209, 2011.

Lee, J., Worden, J., Noone, D., Bowman, K., Eldering, A., LeGrande, A., Li, J.-L. F., Schmidt, G., and Sodemann, H.: Relating tropical ocean clouds to moist processes using water vapor isotope measurements, Atmos. Chem. Phys., 11, 741-752, doi:10.5194/acp-11-741-2011, 2011.
Noone, D., Galewsky, J., Sharp, Z. D., Worden, J., Barnes, J., Baer, D., Bailey, A., Brown, D. P., Christensen, L., Crosson, E., Dong, F., Hurley, J. V., Johnson, L. R., Strong, M., Toohey, D., Van Pelt, A., and Wright, J. S.: Properties of air mass mixing and humidity in the subtropics from measurements of the $\mathrm{D} / \mathrm{H}$ isotope ratio of water vapor at the Mauna Loa Observatory, J. Geophys. Res., 116, D22113, doi:10.1029/2011JD015773, 2011.

Pougatchev, N., August, T., Calbet, X., Hultberg, T., Oduleye, O., Schlüssel, P., Stiller, B., Germain, K. S., and Bingham, G.: IASI temperature and water vapor retrievals - error assessment and validation, Atmos. Chem. Phys., 9, 7971-7989, doi:10.5194/acpd-9-7971-2009, 2009.

Randall, D. A., Harshvardhan, Dazlich, D. A., and Corsetti, T. G.: Interactions among Radiation, Convection, and Large-Scale Dynamics in a General Circulation Model, J. Atmos. Sci., 46, 1943-1970, doi:10.1175/15200469(1989)046<1943:IARCAL>2.0.CO;2, 1989.

Risi, C., Bony, S., Vimeux, F., Frankenberg, C., Noone, D., and Worden, J.: Understanding the Sahelian water budget through the isotopic composition of water vapor and precipitation, J. Geophys. Res., 115, D24110, doi:10.1029/2010JD014690, 2010a.

Risi, C., Bony, S., Vimeux, F., and Jouzel, J.: Water-stable isotopes in the LMDZ4 general circulation model: Model evaluation for present-day and past climates and applications to climatic interpretations of tropical isotopic records, J. Geophys. Res., 115, D12118, doi:10.1029/2009JD013255, 2010b.

Risi, C., Noone, D., Worden, J., Frankenberg, C., Stiller, G., Kiefer, M., Funke, B., Walker, K., Bernath, P., Schneider, M., Bony, S., Lee, J., Brown, D., and Sturm, C.: Process-evaluation of tropospheric humidity simulated by general circulation models using water vapor isotopic observations: 2 . Using isotopic diagnostics to understand the mid and upper tropospheric moist bias in the tropics and subtropics, J. Geophys. Res., 117, D05304, doi:10.1029/2011JD016623, 2012a.

Risi, C., Noone, D., Worden, J., Frankenberg, C., Stiller, G., Kiefer, M., Funke, B., Walker, K., Bernath, P., Schneider, M., Wunch, D., Sherlock, V., Deutscher, N., Griffith, D., Wennberg, P. O., Strong, K., Smale, D., Mahieu, E., Barthlott, S., Hase, F., García, O., Notholt, J., Warneke, T., Toon, G., Sayres, D., Bony, S., Lee, J., Brown, D., Uemura, R., and Sturm, C.: Processevaluation of tropospheric humidity simulated by general circulation models using water vapor isotopologues: 1. Comparison between models and observations, J. Geophys. Res., 117, D05303, doi:10.1029/2011JD016621, 2012b.

Rodgers, C. D.: Inverse methods for atmospheric sounding: theory and practise, World Scientific, 2000.

Rothman, L. S., Barbe, A., Chris Benner, D., Brown, L. R., CamyPeyret, C., Carleer, M. R., Chance, K., Clerbaux, C., Dana, V., Devi, V. M., Fayt, A., Flaud, J. M., Gamache, R. R., Goldman, A., Jacquemart, D., Jucks, K. W., Lafferty, W. J., Mandin, J. Y., Massie, S. T., Nemtchinov, V., Newnham, D. A., Perrin, A., Rinsland, C. P., Schroeder, J., Smith, K. M., Smith, M. A. H., Tang, K., Toth, R. A., Vander Auwera, J., Varanasi, P., and Yoshino, K.: The HITRAN molecular spectroscopic database: edition of 2000 including updates through 2001, J. Quant. Spectrosc. Ra., 82, 5-44, 2003.

Schlüssel, P., Hultberg, T. H., Phillips, P. L., August, T., and Calbet, X.: The operational IASI Level 2 processor, Adv. Space Res., 36, 982-988, 2005. 
Schmidt, G. A., Ruedy, R. A., Miller, R. L., and Lacis, A. A.: Attribution of the present-day total greenhouse effect, J. Geophys. Res., 115, D20106, doi:10.1029/2010JD014287, 2010.

Schneider, M. and Hase, F.: Optimal estimation of tropospheric $\mathrm{H}_{2} \mathrm{O}$ and deltaD with IASI/METOP, Atmos. Chem. Phys., 11, 16107-16146, doi:10.5194/acpd-11-16107-2011, 2011.

Schneider, M., Hase, F., and Blumenstock, T.: Ground-based remote sensing of $\mathrm{HDO} / \mathrm{H}_{2} \mathrm{O}$ ratio profiles: introduction and validation of an innovative retrieval approach, Atmos. Chem. Phys., 6, 4705-4722, doi:10.5194/acp-6-4705-2006, 2006.

Schneider, M., Yoshimura, K., Hase, F., and Blumenstock, T.: The ground-based FTIR network's potential for investigating the atmospheric water cycle, Atmos. Chem. Phys., 10, 3427-3442, doi:10.5194/acp-10-3427-2010, 2010a.

Schneider, T., O'Gorman, P. A., and Levine, X. J.: Water vapor and the dynamics of climate changes, Rev. Geophys., 48, RG3001, doi:10.1029/2009RG000302, 2010b.

Schneider, M., Barthlott, S., Hase, F., González, Y., Yoshimura, K., García, O. E., Sepúlveda, E., Gomez-Pelaez, A., Gisi, M., Kohlhepp, R., Dohe, S., Blumenstock, T., Strong, K., Weaver, D., Palm, M., Deutscher, N. M., Warneke, T., Notholt, J., Lejeune, B., Demoulin, P., Jones, N., Griffith, D. W. T., Smale, D., and Robinson, J.: Ground-based remote sensing of tropospheric water vapour isotopologues within the project MUSICA, Atmos. Meas. Tech. Discuss., 5, 5357-5418, doi:10.5194/amtd-5-53572012, 2012.

Sherwood, S. C., Roca, R., Weckwerth, T. M., and Andronova, N. G.: Tropospheric water vapor, convection, and climate, Rev. Geophys., 48, RG2001, doi:10.1029/2009RG000301, 2010.

Soden, B. J. and Held, I. M.: An Assessment of Climate Feedbacks in Coupled Ocean Atmosphere Models, J. Climate, 19, 33543360, doi:10.1175/JCLI3799.1, 2006.

Strong, M., Sharp, Z. D., and Gutzler, D. S.: Diagnosing moisture transport using D/H ratios of water vapor, Geophys. Res. Lett., 34, L03404, doi:10.1029/2006GL028307, 2007.
Taylor, K. E.: Summarizing multiple aspects of model performance in a single diagram, J. Geophys. Res., 106, 7183-7192, doi:10.1029/2000JD900719, 2001.

Toth, R. A.: HDO and $\mathrm{D}_{2} \mathrm{O}$ Low Pressure, Long Path Spectra in the 600-3100 $\mathrm{cm}^{-1}$ Region: I. HDO Line Positions and Strengths, J. Molec. Spectrosc., 195, 73-97, 1999.

Worden, J., Bowman, K., Noone, D., Beer, R., Clough, S., Eldering, A., Fisher, B., Goldman, A., Gunson, M., Herman, R., Kulawik, S. S., Lampel, M., Luo, M., Osterman, G., Rinsland, C., Rodgers, C., Sander, S., Shephard, M., and Worden, H.: Tropospheric Emission Spectrometer observations of the tropospheric $\mathrm{HDO} / \mathrm{H}_{2} \mathrm{O}$ ratio: Estimation approach and characterization, J. Geophys. Res., 111, D16309, doi:10.1029/2005JD006606, 2006.

Worden, J., Noone, D., and Bowman, K.: Importance of rain evaporation and continental convection in the tropical water cycle, Nature, 445, 528-532, doi:10.1038/nature05508, 2007.

Worden, J., Kulawik, S., Frankenberg, C., Payne, V., Bowman, K., Cady-Peirara, K., Wecht, K., Lee, J.-E., and Noone, D.: Profiles of $\mathrm{CH}_{4}, \mathrm{HDO}, \mathrm{H}_{2} \mathrm{O}$, and $\mathrm{N}_{2} \mathrm{O}$ with improved lower tropospheric vertical resolution from Aura TES radiances, Atmos. Meas. Tech., 5, 397-411, doi:10.5194/amt-5-397-2012, 2012.

Yoshimura, K., Frankenberg, C., Lee, J., Kanamitsu, M., Worden, J., and Röckmann, T.: Comparison of an isotopic atmospheric general circulation model with new quasi-global satellite measurements of water vapor isotopologues, J. Geophys. Res., 116, D19118, doi:10.1029/2011JD016035, 2011.

Zhang, R., Kang, S. M., and Held, I. M.: Sensitivity of Climate Change Induced by the Weakening of the Atlantic Meridional Overturning Circulation to Cloud Feedback, J. Climate, 23, 378389, doi:10.1175/2009JCLI3118.1, 2010.

Zhou, D., Larar, A., Liu, X., Smith, W., Strow, L., Yang, P., Schlüssel, P., and Calbet, X.: Global Land Surface Emissivity Retrieved From Satellite Ultraspectral IR Measurements, IEEE Trans. Geosci. Remote Sens, 49, 1277-1290, doi:10.1109/TGRS.2010.2051036, 2011. 